\title{
Inter-Provincial Responsibility Allocation of Carbon Emission in China to Coordinate Regional Development
}

\section{Feng Wang}

Xi'an Jiaotong University

Xing Ge ( $\nabla$ gexing@stu.xjtu.edu.cn )

Xi'an Jiaotong University

\section{Research Article}

Keywords: Carbon Emission Allowance, Entropy Method, Modified Fixed Cost Allocation Model, Carbon Emission Intensity

Posted Date: May 4th, 2021

DOl: https://doi.org/10.21203/rs.3.rs-421632/v1

License: (c) (i) This work is licensed under a Creative Commons Attribution 4.0 International License.

Read Full License

Version of Record: A version of this preprint was published at Environmental Science and Pollution Research on August 31st, 2021. See the published version at https://doi.org/10.1007/s11356-021-160972. 


\title{
1 Inter-provincial responsibility allocation of carbon emission in 2 China to coordinate regional development
}

\author{
3 Feng Wang $•$ Xing Ge
}

\section{Abstract}

5 To establish the carbon emission trading scheme and achieve the carbon emission reduction goals in China, it 6 is critical to allocate the carbon emission allowance (CEA). Using the entropy method and the modified fixed targets of 30 Chinese provinces in 2030, and further classified China's provinces, from four principles (equity-efficiency-feasibility-sustainability) and three dimensions (economy-society-environment). The results are shown as follows. First, we calculated China's CEA in 2030 is $17567.9 \mathrm{Mt}$. Second, on the whole, China's southern provinces have higher CEA than northern ones. Eastern China has a larger final CEA than western China and central China. Third, Guangdong has the largest final CEA, due to its large population, developed economy, and high energy utilization efficiency. Fourth, in the future, provinces such as Guizhou, Inner Mongolia, Ningxia, Xinjiang, Shaanxi, and Shanxi will take on greater responsibility for carbon emission reduction, while provinces such as Tianjin, Qinghai, Guangxi, and Beijing will be able to sell carbon emission allowances to other provinces.

Keywords Carbon Emission Allowance Entropy Method Modified Fixed Cost Allocation Model Carbon Emission Intensity

\section{Introduction}

The sustainable development of contemporary human beings is facing the severe challenge of global warming. To cope with this challenge, countries around the world have made persistent efforts and implemented many mitigation and adaptation measures. As the second-largest economy and the largest carbon emitter in the world, China is facing huge pressure to reduce emissions (Zhang and Cheng 2009). The Chinese government has put forward a series of emission reduction policies and regarded energy conservation and emission reduction as a long-term national policy. In the Copenhagen Climate Change Conference, China promised it would reduce its CEI by 40-45\% in 2020 compared to the level of 2005 (Cui et al. 2014). It marks that China has entered the era of quantitative control of carbon emission reduction. Furthermore, China pledges to peak $\mathrm{CO} 2$ emissions by around 2030 and strive to achieve it as soon as possible, and by 2030, reduce CO2 per unit of GDP by 60-65\% over the 2005 level (Qin et al. 2017).

China's economy has stepped into the "new normal" phase. When China aims to achieve energy conservation and reducing emissions in coping with the problems in energy and environment, it also needs to address poverty, unemployment, and regional development gaps by promoting its economic growth.

How to effectively and rationally allocate inter-provincial CEA under the constraint of energy conservation, emission reduction, and economic growth? To answer this question is not only a practical problem that needs to be solved urgently in China's practice of tackling climate change, but also a theoretical problem that needs to be settled in the climate change economics with Chinese characteristics. The following four reasons can support this point.

First, when China's overall carbon emissions are approaching a peak, it is facing pressures from the control of overall carbon emissions and the upcoming absolute carbon emission reduction. Considering the negative externality of greenhouse gas emissions, the accomplishment of China's emission reduction targets requires joint efforts from provinces, cities, and firms. Therefore, the allocation of inter-provincial CEA is an important measure to achieve emission reduction targets (Feng and Lu 2016).

Second, as the largest developing country, development is an absolute priority for China. In this case, carbon emission rights are equivalent to development rights, since there are significant differences among

\footnotetext{
Feng Wang

wangfeng123@xjtu.edu.cn

Xing Ge

gexing@stu.xjtu.edu.cn

School of Economics and Finance, Xi' an Jiaotong University, Xi'an 710061, China;
} 
provinces in resource endowment, population distribution, economic development, input-output efficiency, and carbon efficiency. Thus, reasonable and effective allocation of inter-provincial carbon emission rights is conducive to reduce the regional gap and promote sustainable development.

Third, the rational allocation of inter-provincial CEA urges regions to choose between increasing R\&D investment and purchasing carbon emission rights. Carbon emission rights are scarce resources, the increasing purchase on it will increase its price and finally pushes regions to focus on technological innovation for a maximum of their benefits.

Fourth, inter-provincial CEA can lay a fundamental role in establishing a perfect carbon trading market. From 2011 till now, China has opened the prelude of managing climate change with the participation carbon trading market, to effectively control carbon emission, China has placed local pilots of carbon emission trading, and constructed and improved the national carbon market. According to the Coase theorem, the initial allocation of carbon emission rights affects its trading efficiency, and the trading framework of CEA is an effective tool to stimulate and achieve energy conservation and emission reduction (Han et al. 2017). Therefore, a reasonable and effective inter-provincial CEA is conducive to improving the efficiency of carbon emission trading, which is the key to establish and improve China's carbon emission trading market and realize the 2030 carbon emission reduction target (Zhou et al. 2018; Zhang et al. 2014).

We will study China's allocation of inter-provincial carbon emission rights from four principles (equity-efficiency-feasibility-sustainability) and three dimensions (economy-society-environment), The conclusions of this paper have great significance to the establishment of the Chinese carbon emission market, as well as energy-saving, emission reduction, innovation promotion, coordination of regional development.

The remainder of this paper is as follows. Section 2 reviews the relevant literature. Section 3 introduces the research model and data used in this paper. Section 4 provides the empirical results and discussion. The last section presents the conclusions with policy suggestions.

\section{Literature review}

The carbon emission right was originally defined by Dales as the right of a permit holder to emit pollutants to the environment within legally defined limits. Scholars have proposed many allocation principles of CEA, such as the principle of equity, the principle of efficiency, the principle of feasibility, and the principle of sustainability, where equity and efficiency principles are more common. They also introduced some main methods of CEA which include indicator method, game theory method, data envelopment analysis (DEA) method, and synthesis method.

The research on CEA based on equity perspective is earlier. The criteria of equity allocation include the principles of grandfathering, egalitarianism, and the ability to pay, etc. Different criteria correspond to different indicators, but with the continuous development of research, different understandings of equity produced new criteria and indicators of equity distribution.

Rose regards equity as the equal right of all people to pollute and not to be polluted. Schmidt and Heitzig (2014) research CEA from the perspective of historical carbon emission. By comparing the distribution of inter-provincial CEA under the principle of grandfathering, egalitarianism, and the ability to pay, Wu et al. (2010) believed that ability to pay was a more appropriate standard. Zhou et al. (2013) concluded that population and historical carbon emission better reflect the principle of equity by comparing energy consumption, GDP, population, GDP per unit of capital, and historical carbon emission.

However, some scholars indicated that the allocation based on historical carbon emission will lead to insufficient incentives (Cui et al. 2014; Zhou et al. 2017; Zhou and Wang 2016). Pan et al. (2014) believe that carbon emission per unit of capital accumulation is a more appropriate indicator of CEA. Zhou and Wang (2016) calculate the CEA according to the GDP share of each region, which reflects the imbalance of regional development. Han et al. (2017) obtain CEA in the Beijing-Tianjin-Hebei region by constructing comprehensive evaluation indicators. Scholars hold different views on the pros and cons of the criteria and indicators of equity distribution. Although the principle of equity plays a vital role in CEA, absolute equity will discourage other provinces.

The principle of efficiency emphasizes the reduction of potential carbon emission. In the case of the same carbon emission, regions with high carbon emission efficiency can achieve greater output (Ma et al. 2017). The input-output model is used to evaluate the efficiency of carbon emission, and the DEA model is a widely recognized method to evaluate the efficiency of multi-input and multi-output. Based on the traditional DEA model, according to the characteristics of the fixed total Olympic medals, combined with the zero-sum game 
idea, that is, one party gains, one party loses. Lins et al. established the zero-sum gains DEA (ZSG-DEA) model, which applies to the case of fixed total input. Comes and Lins (2008) study the CEA of countries related to the Kyoto Protocol based on the ZSG-DEA model. Fu and Huang (2016) calculate China's inter-provincial CEA in 2020 by using the ZSG-DEA model. Zeng et al. (2016) use the ZSG-DEA model to optimize the CEA efficiency of China's 30 provinces and cities, based on the premise of fixed overall carbon emissions and non-fossil energy consumption. Zhang and Hao (2017) evaluate the carbon emission efficiency of China's 39 industrial sectors in 2020 by using the ZSG-DEA model.

Whereas, CEA is related to regional economic development. If we are only based on the principle of efficiency, it would bring negative effects on the future development of underdeveloped regions which is unfair.

Scholars are more and more concerned with the multi-principle of CEA for the multi-dimensional of the realistic target. CEA with the multi-principle can avoid the extreme results that may occur under a single principle. Yang et al. (2012) discuss the carbon emission reduction potential of different regions regarding the principles of equity and efficiency, based on the cluster analysis. Zhao et al. (2017) integrate the principles of equity and efficiency with the comprehensive indicator method to analyze the CEA of 41 sectors in China. Zhou et al. (2018) obtain the CEA of 71 Chinese cities by applying the DEA model to construct the comprehensive allocation coefficient. Zhou et al. (2018) calculate China's 71 cities CEA by applying the DEA model to construct the comprehensive allocation coefficient. Li et al. (2018) study the CEA of the Pearl River Delta region by using population, GDP, and historical carbon emission to represent the principles of equity, efficiency, and feasibility, respectively. Although these scholars consider multiple principles of CEA, most of them adopt the proportional distribution or ZSG-DEA model in their methods. Wang and Li (2013) calculate China's provinces CEA in 2010 by introducing population indicators in the fixed cost allocation model (FCAM). Fang et al. (2018) built an indicator system of equity, efficiency, feasibility, and sustainability, used factor analysis to calculate the weight of each province, and then found the CEA of China's 31 provinces from 2016 to 2030. In a word, there is no consensus on the principles and indicators of CEA under the overall amount constraint.

Through the summary of the existing research, (1) we find that principles of equity, efficiency, feasibility, and sustainability are relatively comprehensive at present. (2) The comprehensive indexes have been used widely, which can integrate different principles. (3) The ZSG-DEA model is used more extensively in CEA compared with the FCAM model. By comparing FACM and ZSG-DEA, both of them can allocate the overall fixed cost. The difference lies in that ZSG-DEA considers the efficiency of each decision-making unit (DMU) and makes all DMUs relatively effective through iteration, but FCAM regards the element with a fixed amount as new input, and its first two steps can be used to find countless solutions that make the decision unit reach the frontier. the solution iterated by the ZSG-DEA model many times is only one of the countless solutions of the FCAM model. The third step of FCAM elects the CEA that most conforms to the objective function. Theoretical analysis shows that the FCAM method has more advantages than the ZSG-DEA model.

Scholars have many differences in measuring principles and specific research methods and obtained different CEA due to different national backgrounds. Therefore, it is very important to explore a specific CEA method under China's national conditions. Since the 19th communist party of China national congress, coordinated regional development has become a national strategy, the core of which is to narrow the regional gap and pay attention to efficiency. At present, China's regional economic development has not yet been decoupled from carbon emission, so carbon emission right means regional development rights. Any single-principle allocation of carbon emission right will be biased, while the multi-criterion allocation of carbon emission is more conducive to promote regional coordinated development. Also, because the integrated analysis uses a variety of methods or models, it can gather the advantages of a variety of methods, so problem analysis will be more comprehensive and systematic. Therefore, we combine the indicator method with the FCAM model as an integrated analysis.

To sum up, we take China's 30 provinces as research objects and calculate the interval value of CEA of each province in China on the premise of achieving the maximum average value of carbon emission efficiency of each province in China. Then, we modify the FCAM model. We construct an indicator system that includes the four principles (equity-efficiency-feasibility-sustainability) and three dimensions (economy-society-environment). We use the entropy method to get the comprehensive value and embed the comprehensive value into the objective function of the third step of the FCAM. We get China's province final CEA in 2030. Next, we calculated China's provinces CEI in 2030 and the CEI reduction compared to 2015. Finally, China's provinces are divided into three categories according to CEI reduction and four categories according to CEI reduction and economic development. 
The existing literature provides a reference for the further study of this paper. The innovations of this paper are as follows: (1) we construct 12 indicators from the four principles (equity-efficiency-feasibility-sustainability) and three dimensions (economy-society-environment). The indicator system constructed in this paper is more comprehensive than the existing research. (2) We modified the FCAM model by embedding multi-criteria principles and indicators into the original FCAM model. Through the literature review, we find that there are few studies of CEA based on the four principles of equity, efficiency, feasibility, and sustainability. Beasley's (2003) FCAM first realize the optimal of all the average efficiency of DMUs, Second, the fixed total cost is allocated through the principle of proportional convergence, but the proportional convergence idea will expand regional differences. To solve this problem, we innovatively embed the "principle-dimension" multi-criteria index weighted by the entropy method into the objective function. Therefore, under the premise that all provinces reach the frontier, the results of CEA are closer to fairness, efficiency, feasibility, and sustainability.

\section{Methodology and Data}

\section{Modified fixed cost allocation model}

Beasley designed FCAM and divided it into three steps. FCAM takes the total fixed cost as input and aims to maximize the average efficiency of all DMUs. Based on the idea of proportional convergence, the overall fixed cost is distributed to all DMUs (Beasley 2003).

By reviewing the literature, we find that scholars made similar choices for input-output variables, but different treatments for carbon emission. There are two main ways. The first one adheres to the economic production process and treats carbon emission as an undesired output. The other one regarded overall carbon emissions as a limited resource, so CEA is an input variable (Gomes and Lins 2008). Here we choose the second treatment method. In the FCAM model, the input variable is CEA, and the output variables are GDP, population, energy consumption, and capital stock, respectively. The implication is that regions with higher GDP, population size, energy consumption, and capital stock are more efficient under the same CEA. The implication is that regions with higher GDP, population size, energy consumption, and capital stock are more efficient under the same CEA.

Step 1, we take overall carbon emissions as fixed costs to be allocated. Therefore, the input variable of FCAM is the CEA. GDP, population, energy consumption, and capital stock as output variables. China has fixed overall carbon emissions. We use equation (1) to determine the max average value of the input-output efficiency of Chinese provinces.

$$
\begin{aligned}
& \operatorname{Max} \sum_{p=1}^{n} e_{p} / n \\
& \text { s.t. }\left\{\begin{array}{l}
\left(\sum_{i=1}^{s} \alpha_{i} y_{i p}\right) /\left(\sum_{j=1}^{t} \beta_{j} x_{j p}+f_{p}\right)=e_{p} \\
0 \leq e_{p} \leq 1 \\
\sum_{p=1}^{n} f_{p}=F \\
f_{p}=F_{p} \quad \forall p \in S \\
f_{p} \geq 0 \quad p=1,2, \cdots, n \\
\alpha_{i} \geq \varepsilon \quad i=1,2, \cdots, s \\
\beta_{j} \geq \varepsilon \quad j=1,2, \cdots, t
\end{array}\right.
\end{aligned}
$$

Among them, $e_{p}$ is the efficiency value of $\operatorname{DMU} p(p=1,2, \ldots, \mathrm{n})$. In this paper, DMU refers to provinces. $\mathrm{N}$ is equal to 30 , representing 30 provinces. Each DMU has $t$ input variables and s output variables. We take $t=1$, that is, the input variable is the carbon emission allowance. We take $s=4$, that is, the output variables are GDP, population, energy consumption, and capital stock, respectively. $y_{i p}$ stands for output $\mathrm{i}(\mathrm{i}=1,2, \ldots, \mathrm{s})$ of DMU $\mathrm{p}$. $x_{j p}$ refers to input $\mathrm{j}(\mathrm{j}=1,2, \ldots, \mathrm{t})$ of DMU j. $\alpha_{i}$ is the weight of output $\mathrm{i}$, and $\beta_{j}$ is the weight of input $\mathrm{j}$. The set $S$ contains all DMUs assigned. $F p$ is the result of the allocation of the DMU p in the set $S$, and $\varepsilon$ is Archimedean infinitely decimal, with a general value of $10^{-6}$. We set the optimal solution of the objective function in equation (1) is $\sum_{p=1}^{n} e_{p} / n=E^{*}$. 
Step 2, we use the optimal solution of equation (1) as a constraint in the subsequent optimization process to ensure that the average efficiency value of each province in China does not decrease. Then, we use equation (2) to solve the $\max f_{p}$ and the $\min f_{p}$ of the province p's carbon emission rights $f_{p}$.

$$
\begin{aligned}
& \max f_{p}\left(\min f_{p}\right) \\
& \text { s.t. }\left\{\begin{array}{l}
\left(\sum_{i=1}^{s} \alpha_{i} y_{i p}\right) /\left(\sum_{j=1}^{t} \beta_{j} x_{j p}+f_{p}\right)=e_{p} \\
0 \leq e_{p} \leq 1 \\
f_{p}=F_{p} \quad \forall p \in S \\
\sum_{p=1}^{n} f_{p}=F \\
f_{p} \geq 0 \quad p=1,2, \cdots, n \\
\alpha_{i} \geq \varepsilon \quad i=1,2, \cdots, s \\
\beta_{j} \geq \varepsilon \quad j=1,2, \cdots, t \\
\sum_{p=1}^{n} e_{p} / n \geq E^{*}
\end{array}\right.
\end{aligned}
$$

In the optimal solution of the objective function in equation (2), abbreviated the minimum optimal solution is $L_{p}$, and the maximum optimal solution is $U_{p}$. So DMUs have $L_{p} \leq f_{p} \leq U_{p}$. Since the optimization of equation (2) tends to maximize the efficiency of each DMU, that is, $f_{p}$ tends to $L_{p}$, the result is that China's overall carbon emissions rights $\mathrm{F}$ cannot be allocated completely. To solve this problem, Beasley proposes the idea of proportional convergence, that is, the ratio of $f_{p}$ is as the same as possible in $\left[L_{p}, U_{p}\right]$.

Step 3, fixed costs are allocated based on the idea of proportional convergence, according to the results of the first two steps.

$$
\begin{aligned}
& \min \left(Q_{\max }-Q_{\min }\right) \\
& \text { s.t. }\left\{\begin{array}{l}
Q_{\max } \geq\left(f_{p}-U_{p}\right) /\left(U_{p}-L_{p}\right) \\
Q_{\min } \leq\left(f_{p}-U_{p}\right) /\left(U_{p}-L_{p}\right) \\
Q_{\max } \geq 0, Q_{\min } \geq 0 \\
\left(\sum_{i=1}^{s} \alpha_{i} y_{i p}\right) /\left(\sum_{j=1}^{t} \beta_{j} x_{j p}+f_{p}\right)=e_{p} \\
0 \leq e_{p} \leq 1 \\
f_{p}=F_{p} \quad \forall p \in S \\
\sum_{p=1}^{n} f_{p}=F \\
f_{p} \geq 0 \quad p=1,2, \cdots, n \\
\alpha_{i} \geq \varepsilon \quad i=1,2, \cdots, s \\
\beta_{j} \geq \varepsilon \quad j=1,2, \cdots, t \\
\sum_{p=1}^{n} e_{p} / n \geq E^{*}
\end{array}\right.
\end{aligned}
$$

However, the distribution result obtained by equation (3) based on the idea of proportional convergence will widen the gap between high-performance DMUs and low-performance DMUs (Elzen et al. 2005). To solve this problem, based on FCAM, Wang and Li (2013) replaced the idea of proportional convergence with the principle of per capita convergence, to make the final distribution result as fair as possible. However, this constraint only reflects the principle of equity, but it fails to consider the principles of feasibility and sustainability.

Based on the approach of Wang and $\mathrm{Li}$, we further modify the third step of the FCAM model. Equation (4) is the third step of the MFCAM model, which considers the four principles (equity-efficiency-feasibility-sustainability) and three dimensions (economy-society-environment) as comprehensive indicators into the objective function. It makes the ultimate carbon quota for China's provinces becomes more reasonable. 


$$
\begin{aligned}
& \min \left(Q_{\max }-Q_{\min }\right) \\
& \left\{\begin{array}{l}
Q_{\max } \geq\left(f_{p}-U_{p}\right) /\left(U_{p}-L_{p}\right) \\
Q_{\min } \leq\left(f_{p}-U_{p}\right) /\left(U_{p}-L_{p}\right) \\
Q_{\max } \geq 0, Q_{\min } \geq 0 \\
\left(\sum_{i=1}^{s} \alpha_{i} y_{i p}\right) /\left(\sum_{j=1}^{t} \beta_{j} x_{j p}+f_{p}\right)=e_{p} \\
0 \leq e_{p} \leq 1
\end{array}\right. \\
& \text { s.t. }\left\{\begin{array}{l}
0 \leq e_{p} \leq 1 \\
f_{p}=F_{p} \quad \forall p \in S
\end{array}\right. \\
& \sum_{p=1}^{n} f_{p}=F \\
& f_{p} \geq 0 \quad p=1,2, \cdots, n \\
& \alpha_{i} \geq \varepsilon \quad i=1,2, \cdots, s \\
& \beta_{j} \geq \varepsilon \quad j=1,2, \cdots, t \\
& \sum_{p=1}^{n} e_{p} / n \geq E^{*}
\end{aligned}
$$

\section{Among them, $\delta_{p}=c_{p}^{\prime} / F, c_{p}^{\prime}$ is the CEA of province $\mathrm{p}$ that uses the entropy method to weight the} "principle-dimension" multi-criteria. The objective function of equation (4) $\min \sum_{p=1}^{n}\left|\frac{f_{p}}{F}-\delta_{p}\right|$ ensures that the CEA is as close as possible to the principles of equity, efficiency, feasibility, and sustainability on the premise of achieving the optimal average value of overall efficiency.

\section{"Principle-Dimension" multi-criteria indicator system}

Compared with a single-standard CEA scheme, multi-standard indicators can systematically reflect common but differentiated responsibilities. Referring to the existing literature (Fang et al. 2018; Fang et al. 2019; Yi et al. 2011; Feng et al. 2018; Han et al. 2016), we allocated the inter-provincial CEA from the perspective of four principles (equity-efficiency-feasibility-sustainability) and three dimensions (economy-society-environment). The explanation is as follows.

The principle of equity includes three aspects. First, starting from the needs of regional economic development, there are differences in the economic level and industrial structure of developed and underdeveloped areas. Second, everyone has the same rights to products and services. Provinces with larger populations allocate more carbon emission rights. Third, starting from the intergenerational level, people in different eras should have the same rights to public resources. Therefore, we choose GDP per capita, population, and historical carbon emission to represent the economic, social, and environmental dimensions of the equity principle.

The essence of the efficiency principle is that carbon emission rights flow from low-efficiency areas to high-efficiency areas (Ma et al. 2017). Therefore, it is necessary to consider the differences in scientific and technological R\&D investment, energy intensity, and energy consumption structure in different regions. For example, the greater the energy intensity, the greater the potential for emission reduction under the current technological level, and emission reduction can be prioritized. In this case, we choose energy intensity, the proportion of R\&D expenditure in GDP, and the proportion of coal consumption to represent the economic, social, and environmental dimensions of the efficiency principle.

The principle of feasibility means that the distribution of carbon emission rights should take the actual conditions of each region into account, it can ensure the production, ecology, and life of each DMUs are not affected. Meanwhile, it refers to the issue of emission reduction costs and adaptability. For example, when we are considering factors such as economic driving methods, financial payment capacity, and ecological environment quality, the allocation of carbon emission rights should be within a tolerable range. We choose energy consumption elasticity, general public budget revenue, and carbon emission carrying capacity to represent the economic, social, and environmental dimensions of the feasibility principle respectively.

The principle of sustainability refers to the issue that the economy, society, and environment can afford the price of emission reduction, and thus achieve sustainable development. The environmental capacity of different regions is diverse, so the actual carbon sink capacity of the region should be considered. We select the tertiary industry share, urbanization rate, and forest coverage rate to represent the economic, social, and environmental dimensions of the sustainability principle, respectively. 
In summary, we selected 12 indicators under the four principles, three dimensions, and multiple criteria to build a multi-criteria indicator system for the CEA (see Table 1).

256 Table 1 "principle-dimension" Multi-criteria indicators for CEA

\begin{tabular}{|c|c|c|c|}
\hline PrinciplelDimension & Economy & Society & Environment \\
\hline Equity & per capita GDP (-) & Population (+) & $\begin{array}{ll}\text { Historical } & \text { carbon } \\
\text { emission (-) } & \end{array}$ \\
\hline Efficiency & Energy intensity (-) & $\begin{array}{l}\text { Ratio of expenditure on } \\
\text { R\&D to GDP (-) }\end{array}$ & $\begin{array}{l}\text { Proportion of coal } \\
\text { consumption (-) }\end{array}$ \\
\hline Feasibility & $\begin{array}{l}\text { Elasticity coefficient of energy } \\
\text { consumption }(+)\end{array}$ & $\begin{array}{l}\text { General public budget } \\
\text { revenue (-) }\end{array}$ & $\begin{array}{l}\text { Carbon carrying } \\
\text { capacity }(+)\end{array}$ \\
\hline Sustainability & Share of tertiary industry (-) & Urbanization rate (-) & Forest cover rate $(+)$ \\
\hline
\end{tabular}

\section{The entropy method}

The entropy method can evaluate the influence of multiple factors comprehensively. Its principle is as follows. The greater the entropy of the index, the more information it carries, and thus the we0ight in the comprehensive evaluation is greater. The weighting process of the entropy method is relatively objective, so the result has more reference value (Shannon 1949). The specific steps of this method are as follows.

The first step is to standardize the raw data. Due to the dimension difference of the original data, we use equation (5) to standardize the original data and make it becomes dimensionless standardized data.

$$
y_{p q}=\left\{\begin{array}{l}
\frac{x_{p q}-\min \left(x_{. q}\right)}{\max \left(x_{. q}\right)-\min \left(x_{. q}\right)}, \text { for the positive indicator } \\
\frac{\max \left(x_{. q}\right)-x_{p q}}{\max \left(x_{. q}\right)-\min \left(x_{. q}\right)}, \text { for the positive indicator }
\end{array}\right.
$$

Among them, $x_{p q}(\mathrm{p}=1,2, \ldots, \mathrm{n} ; \mathrm{q}=1,2, \ldots, \mathrm{m})$ is the original data, $\mathrm{n}$ is the number of samples, and $\mathrm{m}$ is the number of indicators. We take $\mathrm{n}$ as 30 , representing 30 provinces. We take $\mathrm{m}$ as 12 , representing 12 indicators. $\max \left(x_{. q}\right)$ and $\min \left(x_{. q}\right)$ are the maximum and minimum values of the $\mathrm{q}^{\text {th }}$ indicator, respectively, and $y_{p q}$ is the standardized data.

In the second step, through the equation (6) and (7) to calculate the information entropy value $e_{q}$ of each indicator.

$$
\begin{gathered}
u_{p q}=\frac{y_{p q}}{\sum_{p=1}^{n} y_{p q}} \ldots . \\
e_{q}=-\frac{\sum_{p=1}^{n} u_{p q} \ln u_{p q}}{\ln (n)}
\end{gathered}
$$

The third step is to calculate the weight $w_{q}$ of each indicator by equation (8).

$$
w_{q}=\frac{1-e_{q}}{m-\sum_{q=1}^{m} e_{q}}
$$

The fourth step is to calculate the comprehensive score $h_{p}$ of each province by equation (9).

$$
h_{p}=\sum_{q=1}^{m} w_{q} \cdot y_{p q}
$$

\section{Data}

GDP

China's GDP growth rate in 2019 was $6.1 \%$, as China's economy entered a new normal. The potential economic growth rate will slow down because of the decline in the total fertility rate and the aging population will supply-side factors ( $\mathrm{Li}$ et al. 2020). Drawing on their estimated results of China's potential GDP growth rate from 2020 to 2030 (see Fig. 1), we predict China's provincial GDP in 2030, assuming that the potential GDP growth rate of each province is equal to China's potential GDP growth rate. The data comes from the National Bureau of Statistics of China. 


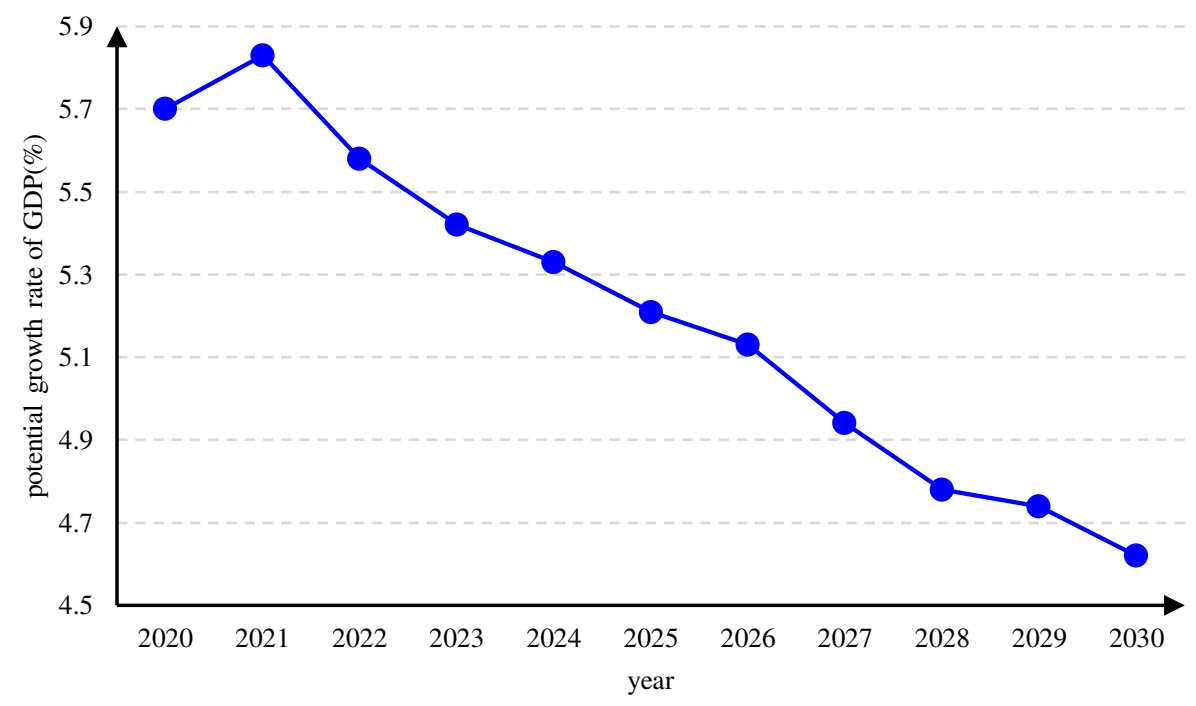

Fig. 1 Forecast values of China's potential economic growth rate from 2020 to 2030

\section{Population}

The methods of predicting population mainly include the exponential model, logistic population growth model, Leslie matrix economic model, and cohort-component method. The cohort-component method uses a specific year as the base year, calculates the population size and structure of next year through fertility rate, death rate, and emigration rate (a small proportion) by age groups recursively. Referring to the practice of Shang et al. (2016), we use the cohort-component method to predict population. This method has four steps. First, estimate the future surplus of the age-specific population. Second, calculate the number of births. Then, calculate the future margin of the birth population. Finally, calculate the number of people in the coming years. The data comes from the National Bureau of Statistics of China. Besides, we refer to the 2013 China Population and Development Research Center's "National Survey of Fertility Willingness" in 29 provinces.

\section{Energy consumption}

The "Energy Production and Consumption Revolution Strategy (2016-2030)" proposes to limit China's total energy consumption to less than 6 billion tons of standard coal by 2030. Assuming that China's total energy consumption in 2030 is 6 billion tons of standard coal, and the energy consumption proportion of China's provinces in 2030 is equal to the average value of the 2013-2017 proportion. We estimate the energy consumption of China's provinces in 2030. The data comes from the China Energy Statistical Yearbook (2014-2018).

\section{Capital stock}

Regarding the measurement of capital stock, the more recognized method is the perpetual inventory method initiated by Goldsmith. The principle is that capital stock is the weighted sum of past investments. Assuming that the relative efficiency of capital goods is geometrically decreasing, and the replacement rate is equal to the depreciation rate. We use equation (10) to estimate the capital stock.

$$
K_{t}=I_{t}+\left(1-\delta_{t}\right) K_{t-1}
$$

Among them, $K_{t}$ and $K_{t-1}$ represent the capital stock in year $t$ and $t-1$ respectively. It is the new investment in year $t$, and $\delta_{t}$ represents the capital depreciation rate in year $t$. Shan (2008) estimated the capital stock of China's provinces from 1952 to 2006. On this basis, we used equation (10) to calculate the capital stock of China's provinces from 2007 to 2017 and converted it into a constant price in 2000. The total fixed capital formation and fixed asset formation price index obtained from the National Bureau of Statistics of China. Finally, we use the GM $(1,1)$ model to predict the capital stock of China's provinces from 2018 to 2030.

\section{Initial carbon emission allocation}

According to the IPCC guidelines, the historical carbon emission calculation of fossil fuel combustion is shown in equation (10).

$$
C E_{i j}=A D_{i j} \times N C V_{i} \times C C_{i} \times O_{i j}
$$

Among them, $C E_{i j}$ refers to the carbon emission of sector $j$ burning fossil fuel $i, A D_{i j}$ represents the consumption of sector $j$ burning fossil fuel $i . N C V_{i}$ refers to the calorific value per unit of fossil fuel $i$ combustion. $C C_{i}$ refers to the carbon emission contained in each net calorific value produced by fossil fuel $i . O_{i j}$ refers to the oxidation rate in the combustion of fossil fuels. We refer to the research of Shan et al. (2018) about carbon emission from 
fuel combustion. It included 47 sectors and 26 types of fossil fuels. The fossil fuel loss during transportation and conversion and non-energy use of fossil fuel as raw material were removed from the total fossil fuel consumption to avoid double counting. Our historical carbon emission data comes from China Emission Accounts \& Datasets ${ }^{1}$. In 2015, the Chinese government proposed a goal of reducing CEI by $60-65 \%$ compared to 2005 (Qin et al. 2017). Regarding the initial value of carbon emission in 2030, any fixed allocation value of the total amount of carbon emission rights can be selected. Here, we take another approach, assuming that the proportion of the initial carbon emission of China's provinces in 2030 is consistent with the average of the proportion from 2011 to 2015, the China's provinces CEA in 2030 is calculated as the initial value of the optimization function.

\section{China's overall carbon emissions forecast in 2030}

The Chinese government proposed to achieve peak carbon emission no later than 2030 and lower CEI by $60-65 \%$ compared to that in 2005. The determination of overall carbon emissions reduction targets in 2030 is a prerequisite for the CEA of China's provinces. Referring to $\mathrm{Li}$ et al. 's paper (2020), we set a $65 \%$ reduction target in CEI. Then, the CEI reduction target is converted to the overall carbon emissions target. We calculate the overall carbon emissions by equation (12) and (13).

$$
\begin{aligned}
& C E I_{2005}=\frac{C E A_{2005}}{G D P_{2005}} \\
& C E A_{2030}=C E I_{2005} \times G D P_{2030} \times(1-65 \%)
\end{aligned}
$$

Where $\mathrm{CEI}_{2005}$ represents the CEI in 2005. $C E A_{t}$ and $G D P_{t}$ represent overall carbon emissions and gross domestic product in the year $(\mathrm{t}=2015 ; 2030)$, respectively.

First, according to equation (12), we calculated that China's CEI in 2005 was $2.92 \mathrm{t} / 10$ thousand yuan. Secondly, under the goal of achieving a 65\% reduction in CEI by 2030, the target for China's CEI in 2030 is calculated to be $1.02 \mathrm{t} / 10$ thousand yuan. We refer to the latest results of the Macroeconomic Research Center of the Chinese Academy of Social Sciences and calculate that China's GDP in 2030 is 171911.55 billion yuan. Finally, we use equation (13) to calculate China's overall carbon emissions in 2030 is 17567.9 Mt.

\section{"Principles-Dimensions" multi-criteria indicators}

Table 2 shows the data sources for the multi-criteria indicators. We select the average value of each indicator from 2011 to 2015, apply the entropy method to calculate the multi-criteria CEA of China's province.

\footnotetext{
1 http://ceads.net
} 
Table 2 Multi-criteria indicators and data source

\begin{tabular}{|c|c|c|c|c|}
\hline Principle & Dimension & Indicator & \multicolumn{2}{|l|}{ Data source } \\
\hline Equity & Economic & per capita GDP (-) & \multicolumn{2}{|c|}{ China Statistical Yearbooks 2012-2016 } \\
\hline & Social & Population (+) & \multicolumn{2}{|c|}{ National Bureau of Statistics of China } \\
\hline 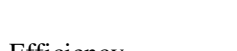 & Environmental & Historical carbon emission (-) & \multicolumn{2}{|l|}{ CEADs } \\
\hline Efficiency & Economic & Energy intensity (-) & \multicolumn{2}{|c|}{ China Statistical Yearbooks 2012-2016 } \\
\hline & Social & Ratio of expenditure on R\&D to GDP (-) & \multicolumn{2}{|c|}{ China Statistical Yearbooks 2012-2016 } \\
\hline & Environmental & Proportion of coal consumption (-) & \multicolumn{2}{|c|}{ China Energy Statistical Yearbooks 2012-2016 } \\
\hline Feasibility & Economic & Elasticity ratio of energy consumption ${ }^{\mathrm{a}}(-)$ & \multicolumn{2}{|c|}{ China Statistical Yearbooks 2012-2016 } \\
\hline & Social & General public budget revenue (+) & \multicolumn{2}{|c|}{ China Statistical Yearbooks 2012-2016 } \\
\hline & Environmental & Carbon carrying capacity $(+)$ & \multicolumn{2}{|c|}{ China Statistical Yearbooks 2012-2016 } \\
\hline Sustainability & Economic & Share of tertiary industry (-) & \multicolumn{2}{|c|}{ China Statistical Yearbooks 2012-2016 } \\
\hline & Social & Urbanization rate (-) & \multicolumn{2}{|c|}{ China Statistical Yearbooks 2012-2016 } \\
\hline & Environmental & Forest cover rate $(+)$ & \multicolumn{2}{|c|}{ China Statistical Yearbooks 2012-2016 } \\
\hline \multicolumn{5}{|c|}{$\begin{array}{l}\text { Average annual growth rate of energy consumption } \\
\text { Average annual growth rate of national economy } \\
\text {. NEP. } 44 \div 12, \text { NEP refers to the amount of carbon absorbed by per } \mathrm{hm}^{2} \text { of vegetation in one year. The NEP of China's provinces can be seen in Table } 3 \text {. } \\
\text { carbon by forest zones in China }\end{array}$} \\
\hline Climatic zone & \multicolumn{3}{|c|}{ 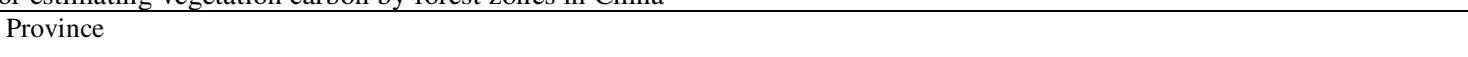 } & $\mathrm{NEP}\left(\mathrm{t} * \mathrm{hm}^{-2 *} \mathrm{a}^{-1}\right)$ \\
\hline warm temperate & \multicolumn{3}{|c|}{ Beijing, Tianjin, Hebei, Shanxi, Shandong, Henan, Shaanxi, Gansu, Qinghai, Ningxia } & 1.43 \\
\hline Cold and temperate & \multicolumn{3}{|c|}{ Inner Mongolia, Liaoning, Jilin, Heilongjiang, Xinjiang } & 1.78 \\
\hline Subtropics & \multicolumn{3}{|c|}{ Shanghai, Jiangsu, Zhejiang, Anhui, Fujian, Jiangxi, Hubei, Hunan, Guangdong, Guangxi, Chongqing, Sichuan, Guizhou, Yunnan } & 2.84 \\
\hline Tropic & \multicolumn{3}{|l|}{ Hainan } & 2.51 \\
\hline
\end{tabular}


The forecast results of input-output indicators of MFCAM

358 Through the above calculations, we get the input and output variables value of the MFCAM model. Table 4 shown the forecast results of GDP, population, energy consumption, capital stock, and initial carbon emission of Chinese provinces in 2030.

361 Table 4 The forecast results of input and output indicators of China's provinces in 2030

\begin{tabular}{|c|c|c|c|c|c|}
\hline Province & $\begin{array}{l}\text { GDP } \quad(100 \\
\text { million yuan })\end{array}$ & $\begin{array}{l}\text { Population ( } 10 \\
\text { thousand persons })\end{array}$ & $\begin{array}{l}\text { Energy consumption } \\
\text { ( } 10 \text { thousand tons } \\
\text { of SCE) }\end{array}$ & $\begin{array}{l}\text { Capital stock ( } 100 \\
\text { million yuan) }\end{array}$ & $\begin{array}{c}\text { Initial value of } \\
\text { carbon } \\
\text { (Mt) }\end{array}$ \\
\hline Beijing & 61819.0 & 2471.0 & 9255.6 & 162306.1 & 143.0 \\
\hline Tianjin & 24650.3 & 1674.3 & 10880.0 & 366455.9 & 215.0 \\
\hline Hebei & 61352.7 & 8572.6 & 39864.7 & 429389.1 & 1010.7 \\
\hline Shanxi & 29757.8 & 4229.2 & 26428.4 & 202481.9 & 1920.7 \\
\hline Inner Mongolia & 30082.6 & 2892.5 & 25276.3 & 387498.8 & 1287.6 \\
\hline Liaoning & 43534.7 & 4891.1 & 28934.7 & 294723.5 & 831.9 \\
\hline Jilin & 20495.2 & 3096.4 & 11115.9 & 303494.8 & 388.6 \\
\hline Heilongjiang & 23791.1 & 4288.9 & 16296.5 & 235264.9 & 583.6 \\
\hline Shanghai & 66684.7 & 2756.9 & 15395.1 & 140919.0 & 266.4 \\
\hline Jiangsu & 174127.6 & 9015.1 & 40709.4 & 615450.4 & 991.1 \\
\hline Zhejiang & 108973.2 & 6452.3 & 26372.0 & 334178.3 & 613.2 \\
\hline Anhui & 64864.7 & 7106.6 & 16564.8 & 299243.9 & 585.0 \\
\hline Fujian & 74094.4 & 4528.1 & 16278.7 & 428332.6 & 343.6 \\
\hline Jiangxi & 43269.1 & 5340.4 & 11204.9 & 172410.7 & 249.4 \\
\hline Shandong & 124205.9 & 11297.1 & 50202.0 & 704702.5 & 1577.9 \\
\hline Henan & 94829.7 & 10911.2 & 30590.7 & 853971.2 & 918.6 \\
\hline Hubei & 80094.9 & 6659.3 & 22104.7 & 446281.0 & 443.7 \\
\hline Hunan & 69475.4 & 7751.8 & 20833.1 & 383052.8 & 418.6 \\
\hline Guangdong & 188178.5 & 13066.6 & 40691.7 & 732021.3 & 800.9 \\
\hline Guangxi & 37116.5 & 5552.0 & 13113.5 & 382427.6 & 289.3 \\
\hline Hainan & 9278.5 & 1070.6 & 2567.8 & 76946.0 & 89.7 \\
\hline Chongqing & 41256.2 & 3346.3 & 11876.7 & 191967.4 & 230.3 \\
\hline Sichuan & 81471.2 & 9171.3 & 26876.9 & 325526.1 & 480.9 \\
\hline Guizhou & 29308.1 & 4030.0 & 13314.2 & 243419.2 & 479.3 \\
\hline Yunnan & 40588.5 & 5483.2 & 14113.8 & 448635.2 & 300.0 \\
\hline Shaanxi & 45079.1 & 4351.5 & 15595.8 & 312724.4 & 794.1 \\
\hline Gansu & 15237.1 & 3030.1 & 9983.6 & 109569.1 & 279.4 \\
\hline Qinghai & 5183.6 & 679.9 & 5418.0 & 128985.0 & 96.3 \\
\hline Ningxia & 6551.3 & 797.8 & 7281.3 & 116667.4 & 303.0 \\
\hline Xinjiang & 23763.9 & 2758.0 & 20859.0 & 241845.4 & 636.3 \\
\hline
\end{tabular}

\section{Results and discussion}

\section{Inter-provincial CEA under the "principles-dimensions" multi-criteria}

365 We calculate China's province CEA from the from four principles

366 (equity-efficiency-feasibility-sustainability) and three dimensions (economy-society-environment). As can 367 be seen from Fig. 2, China's southern provinces have higher CEA than northern ones under the 368 "principles-dimensions" multi-criteria. 


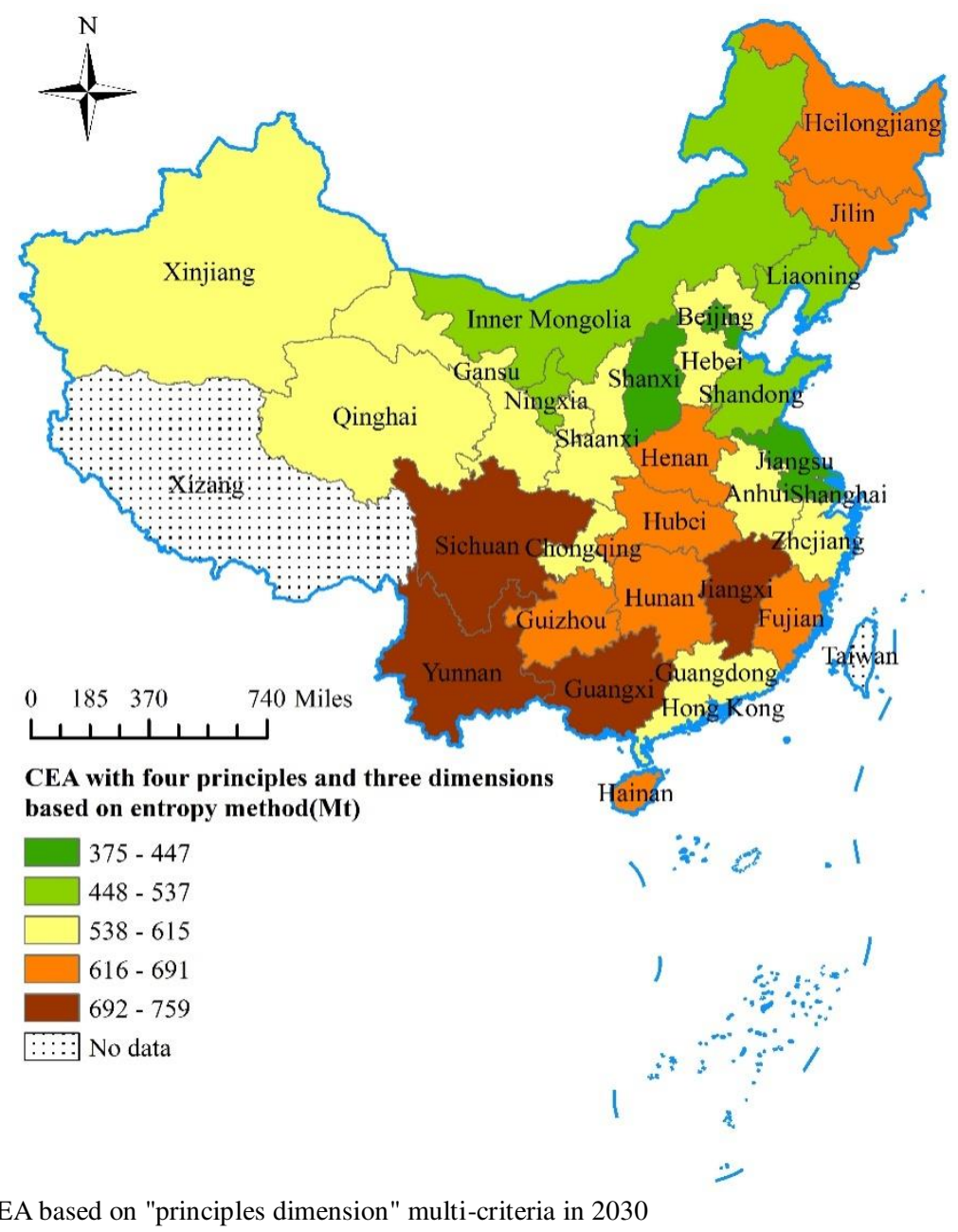

Final CEA of China's province under the MFCAM model

372 We calculate the final CEA of China's province by using the MFCAM model. There are three steps. In the first step, we calculated the optimal average efficiency of all China's provinces is $E^{*}=1$ through equation (1). In the second step, we calculated the $L_{p}$ and $U_{p}$ of China's province CEA under the constraint of the optimal average efficiency value of equation (2) (see Fig. 3). In the third step, we calculated the final CEA using the MFCAM model embedded with "principles-dimensions" multi-criteria. First, we take $L_{p}$ and $U_{p}$ of China's province CEA calculated by equation (2) as the constraints of equation (4). Secondly, we embed the "principle-dimension" multi-criterion CEA of China's provinces into the objective function of equation (4). Finally, we obtained the final CEA of China's province in 2030 (see Fig. 3). 


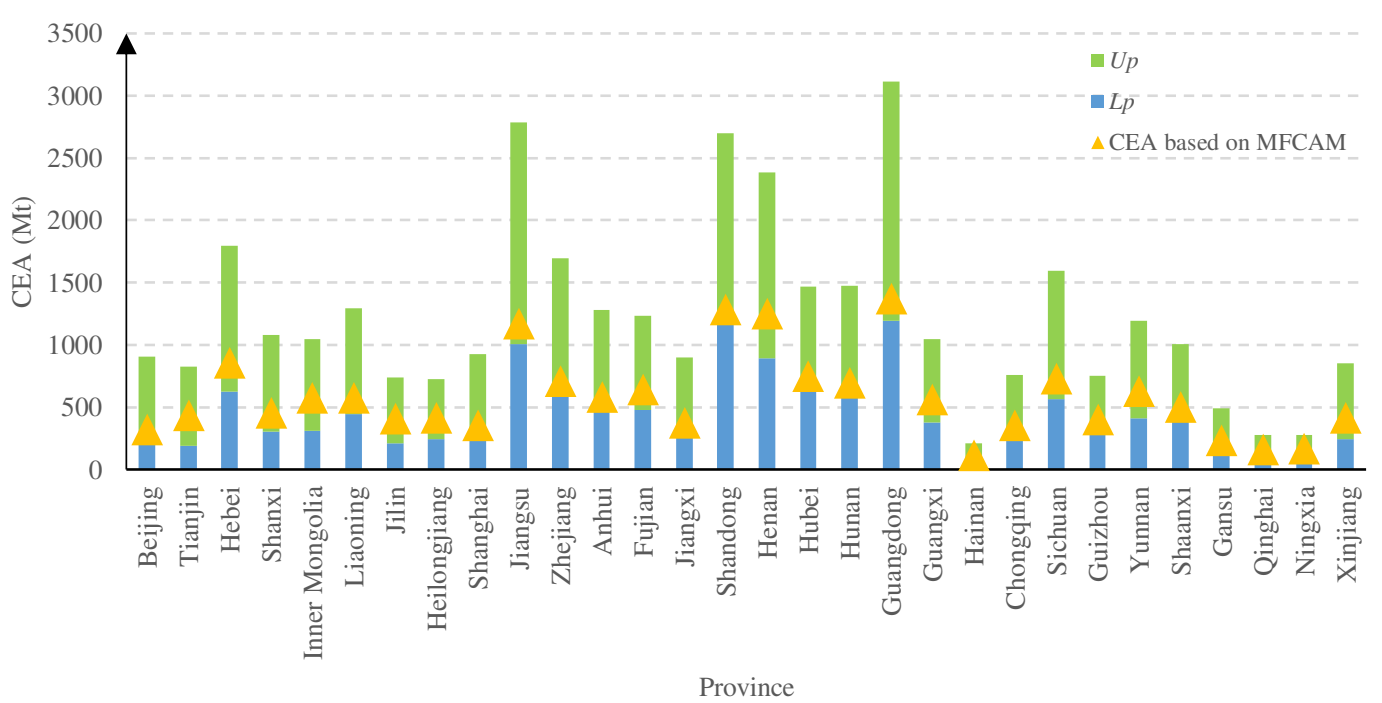

Fig. 3 Provincial final CEA in 2030 based on MFCAM

The position of the triangle in Fig. 3 represents the final CEA of China's provinces in 2030. As can be seen from Fig. 3, Guangdong, Shandong, Henan, and Jiangsu are the four provinces with the most final CEA in 2030, all exceeding 1000 Mt. Similar to the conclusion of Kong et al. (2019), our results also show that Guangdong province has the largest final CEA. We conclude that the CEA of Guangdong province accounts for $7.82 \%$ of China's overall carbon emissions, which is about 1374 Mt. Because Guangdong province has an advanced economic development model, a large population (About 8\% of China's population), and high energy efficiency. However, the historical carbon emission in Guangdong province was relatively high, which adversely affect Guangdong's final CEA in 2030. Gansu, Qinghai, Ningxia, and Hainan are the four regions with the least final CEA in 2030. Among them, Hainan has the smallest CEA, accounting for $0.65 \%$ of China's overall carbon emissions, which is about $114 \mathrm{Mt}$. Because the population of Hainan accounts for only $0.66 \%$ of China's population, and its carbon emission capacity is relatively weak.

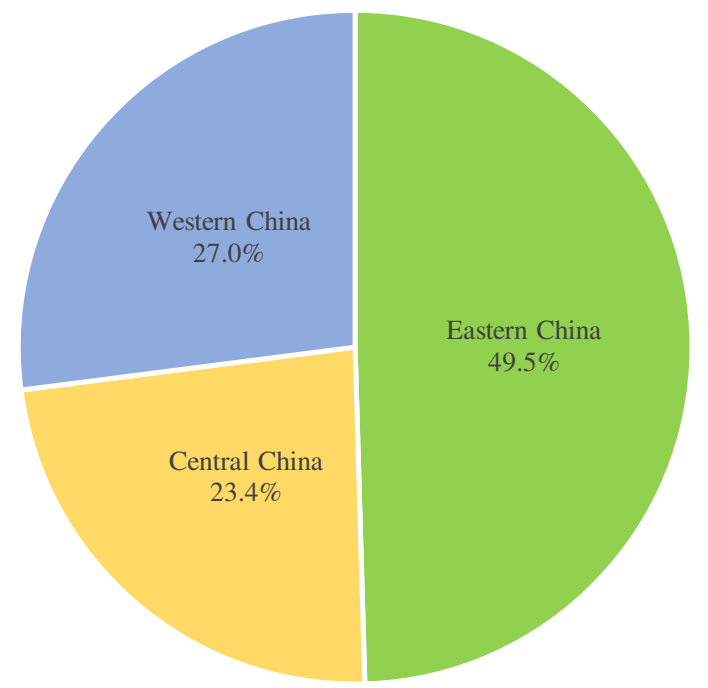

Fig. 4 The proportion of China regional final CEA in 2030 based on MFCAM

Fig. 4 shows the proportion of the final CEA for eastern, central, and western China under the MFCAM model in 2030. Among them, eastern China received the most final CEA, about $8702.9 \mathrm{Mt}$, accounting for $49.5 \%$ of China's overall carbon emissions. Western China received the second-highest final CEA, about 4749.1 Mt, accounting for $27.0 \%$ of China's overall carbon emissions. Central China received the least final CEA, about $4116.0 \mathrm{Mt}$, accounting for $23.4 \%$ of China's overall carbon emissions. 


\section{One-dimensional classification of China's provinces}

According to the final CEA of China's provinces in 2030 under the MFCAM model (see Fig. 3), we calculated the CEI for China's provinces in 2030 and compared them with the data in 2015. Finally, we calculated the CEI reduction tasks that China's provinces need to complete in 2030 compared to 2015.

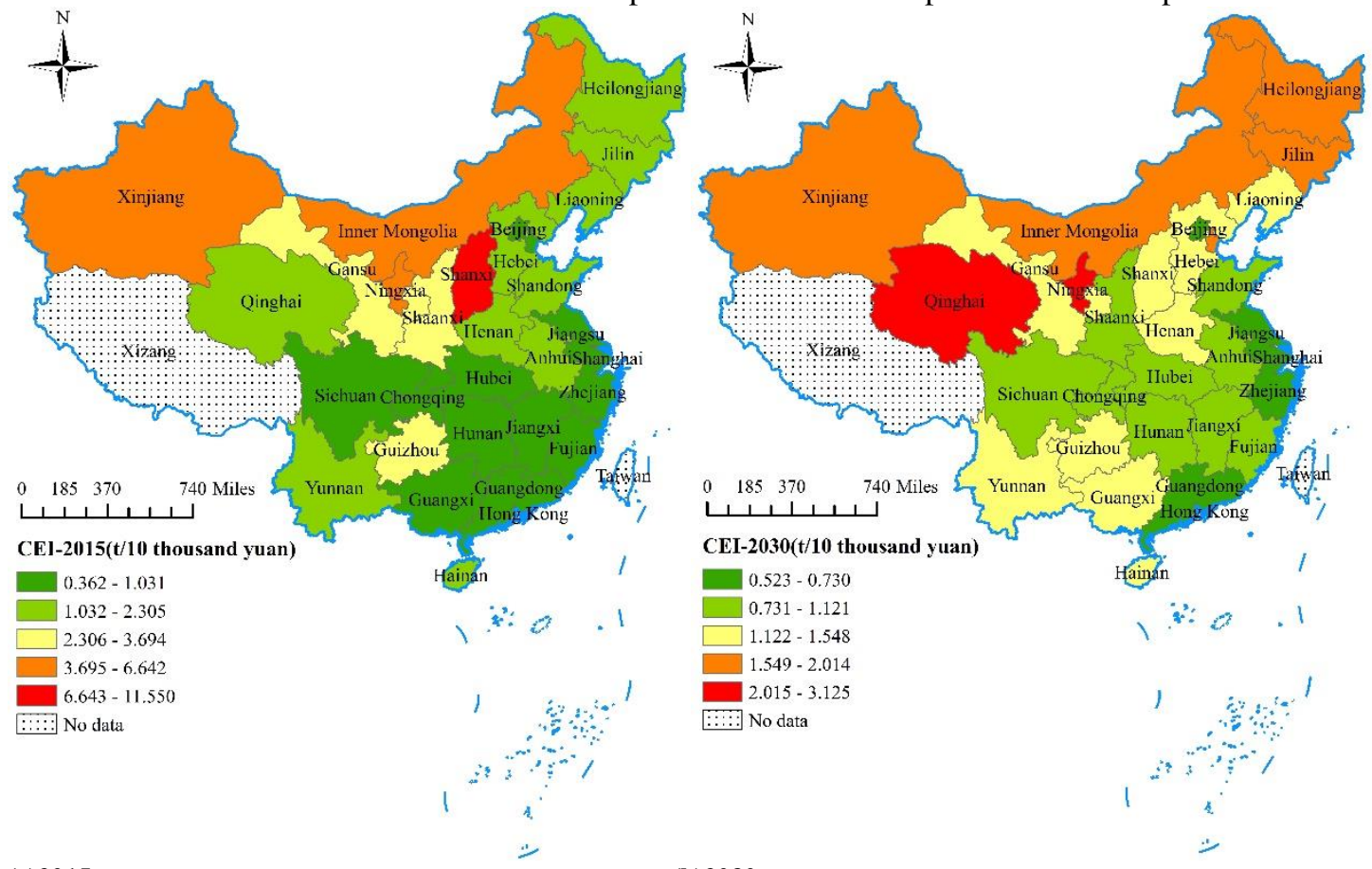

(a) 2015

(b) 2030

Fig. 5 The distribution of CEI of China's provinces in 2015 and 2030

Fig. 5(a) shows the distribution results of China's provinces CEI in 2015. Among them, regions of Shanxi, Ningxia, Xinjiang, and Inner Mongolia have larger CEI. As a large province of energy and carbon emission, Shanxi has the highest CEI, about $11.550 \mathrm{t} / 10$ thousand yuan. The pillar industries of Shanxi province are Coal and steel, which are the industries of high energy consumption, high pollution, and high emission. Among them, coal and non-fossil fuels account for $90 \%$ and $3 \%$ of total energy consumption, respectively. Although Ningxia has actively carried out coal equivalent and reduction substitution in recent years, and vigorously developed renewable energy, due to the continuous growth of investment in the Ningdong base, the high carbon emission characteristics of energy and industrial structure still appear. Xinjiang shows high energy consumption and underutilized in the process of industrialization and urbanization. Inner Mongolia is also a large energy region, rich in mineral resources, with a significant coal consumption proportion, high energy consumption, and high emission. Its economic development is highly dependent on energy consumption. What's more, China's southeastern coastal provinces CEI was uniformly low, which are the country's most economically developed regions. In 2015, the CEI of Beijing, Tianjin, Shanghai, and Guangdong were $0.362 \mathrm{t} / 10$ thousand yuan, $0.498 \mathrm{t} / 10$ thousand yuan, $0.644 \mathrm{t} / 10$ thousand yuan, and $0.696 \mathrm{t} / 10$ thousand yuan, respectively. The emphasis of economic development in the southeast coastal areas is to transform industrial technology, develop new and technology-intensive industries. Therefore, the production process consumes fewer resources.

Fig. 5(b) shows the distribution results of China's provinces CEI in 2015. CEI of northern China is generally higher. For example, Qinghai and Ningxia have the highest CEI, with 3.125 t/10 thousand yuan and 2.552 $\mathrm{t} / 10$ thousand yuan, respectively. CEI of southern China is generally lower. Among them, Shanghai's CEI is relatively low, about $0.532 \mathrm{t} / 10$ thousand yuan. Zhejiang, Jiangsu, and Guangdong also have low CEI ( $0.656 \mathrm{t} / 10$ thousand yuan, $0.675 \mathrm{t} / 10$ thousand yuan, and $0.730 \mathrm{t} / 10$ thousand yuan, respectively). 


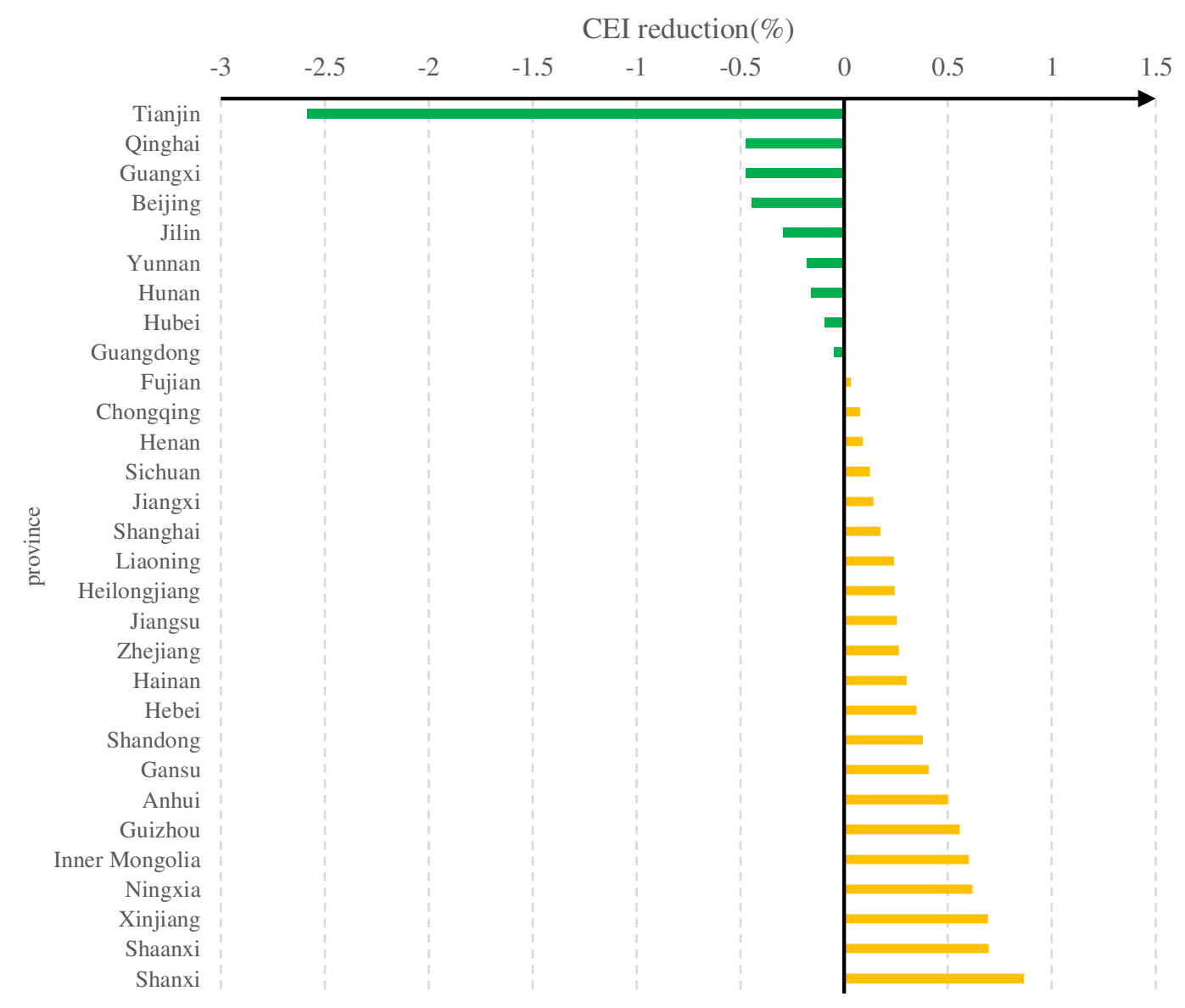

Fig. 6 The CEI reduction of China's provinces during 2015-2030

To know the carbon emission reduction tasks of China's provinces, we calculated the CEI reduction in 2030 compared with 2015. The results show in Fig. 6. From 2015 to 2030, the CEI of Guangdong and Fujian have changed very little. Guizhou, Inner Mongolia, Ningxia, Xinjiang, Shaanxi, and Shanxi have seen their CEI decline by more than $50 \%$, and these provinces will take on a greater responsibility to reduce carbon emission in the future. In contrast, CEI is increased in Tianjin, Qinghai, Guangxi, and Beijing, which will be able to sell carbon emission allowances to other provinces in the future. We use the natural breakpoint method2 to classify China's provinces into category A, category B, and category $\mathrm{C}$ according to the magnitude of the reduction in CEI. Category $\mathrm{A}$ has a small emission reduction task, refers to provinces CEI with a decline of no more than $-258.6 \%$. Tianjin belongs to category A. Category $\mathrm{B}$ has a moderate emission reduction task, includes provinces with a CEI reduction of $-258.5-14.1 \%$. There are 13 provinces in category B, namely, Qinghai, Guangxi, Beijing, Jilin, Yunnan, Hunan, Hubei, Guangdong, Fujian, Chongqing, Henan, Sichuan, and Jiangxi. Category C refers to provinces with a reduction rate between $14.2 \%$ and $86.7 \%$, with high emission reduction tasks. There are 16 provinces in category C, namely Shanghai, Liaoning, Heilongjiang, Jiangsu, Zhejiang, Hainan, Hebei, Shandong, Gansu, Anhui, Guizhou, Inner Mongolia, Ningxia, Xinjiang, Shaanxi, and Shanxi.

\section{Two-dimensional classification of China's provinces}

Considering the difference in economic development among China's provinces, the carbon emission reduction path cannot be analyzed only from the perspective of CEI reduction. Therefore, we analyze the carbon emission reduction path from the two dimensions of economic development and CEI reduction. As shown in Fig. 7, in the two-dimensional quadrant, the vertical axis represents economic development measured by per capita GDP, and the horizontal axis represents emission reduction tasks measured by CEI reduction. Then, we use the average per capita GDP of China's provinces (108,500 yuan/person) and the average DECLINE in CEI $(9.47 \%)$ as the dividing lines, respectively. Finally, we get four zones in the first quadrant, which are high economic development with low emission reduction task zones, high economic

\footnotetext{
2 The natural breakpoint method can minimize the difference with class and maximize the difference between classes by grouping similar values appropriately.
} 
development with high emission reduction task zones, low economic development with low emission reduction task zones, and low economic development with high emission reduction task zones, respectively.

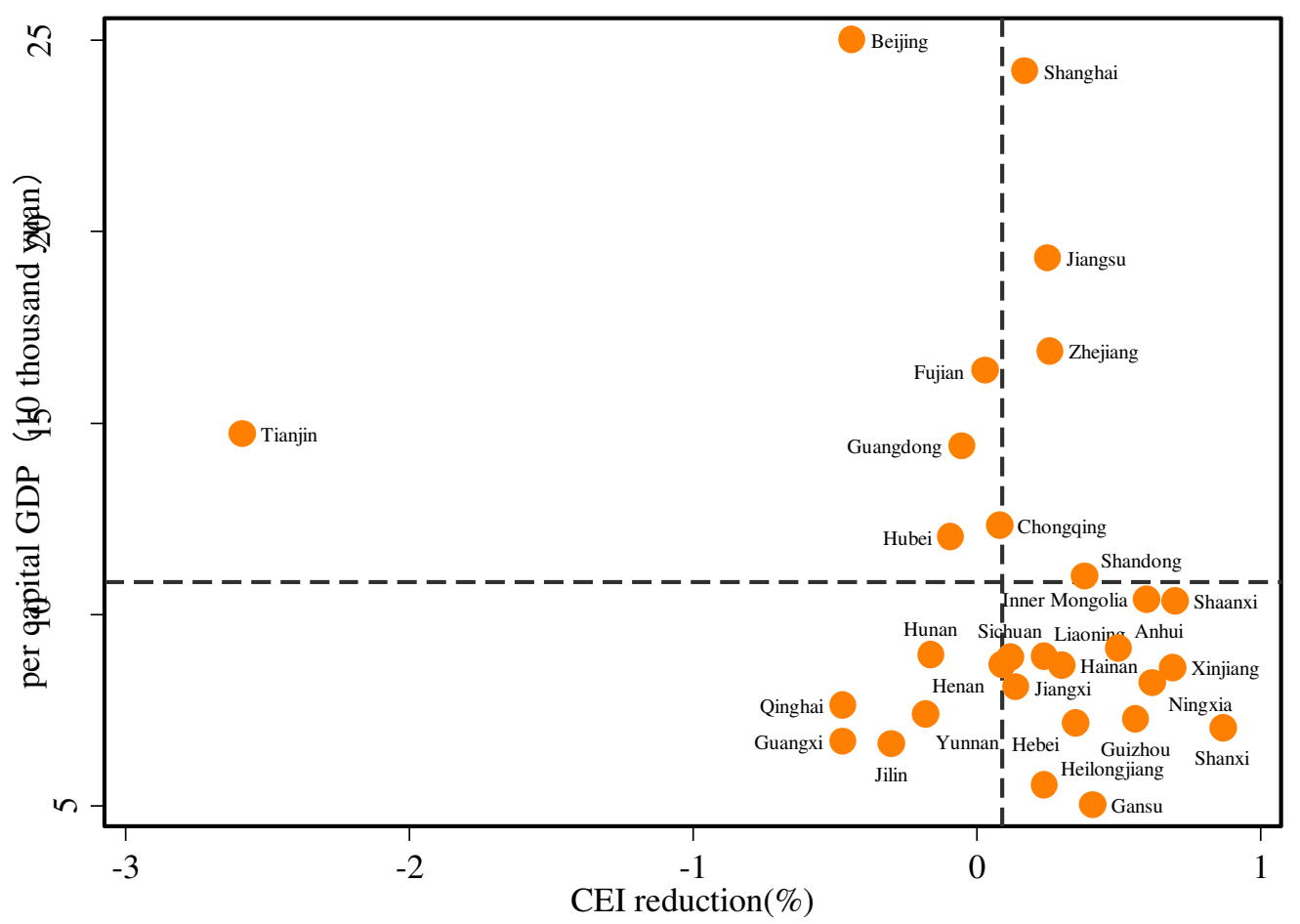

Fig. 7 The scatter plot of per capital GDP and carbon intensity reduction in 2030

The areas with high economic growth and low emission reduction task zones include Tianjin, Beijing, Fujian, Guangdong, and Hubei. These five regions have low emission reduction tasks and high levels of economic development. The low levels of economic development and low emission reduction task zones include Qinghai, Guangxi, Yunnan, Jilin, Hunan, and Henan. These six regions have small emission reduction tasks, but the level of economic development is also low. The high levels of economic development and high emission reduction task zones include Shanghai, Jiangsu, Zhejiang, Chongqing, and Shandong. These five regions have high emission reduction tasks, but their economic development levels are relatively high. The low levels of economic development and high emission reduction task zones include Inner Mongolia, Liaoning, Sichuan, Hainan, Jiangxi, Hebei, Heilongjiang, Gansu, Shaanxi, Anhui, Xinjiang, Ningxia, Shanxi, and Guizhou. These 14 regions have high emission reduction tasks on the one hand, and economic development is backward. Regions in the last three zones should make full use of resource endowments, energy consumption structure and industrial structure, etc., and move to high economic growth and low emission reduction task zones, further realize sustainable development.

\section{Conclusions and policy suggestions}

Based on the realization of China's carbon emission reduction target in 2030, we use MFCAM studied China's provincials CEA from "principle-dimension" multi-criteria. First, we turned the CEI reduction target into China's overall carbon emissions in 2030. Secondly, on the premise of achieving China's 2030 carbon emission reduction target, we construct the indicators system from four principles (equity-efficiency-feasibility-sustainability) and three dimensions (economy-society-environment). We use the entropy method to make "principle-dimension" multi-criteria into a comprehensive indicator. Thirdly, we modified the FCAM model, embed the comprehensive indicator of "principle-dimension" multi-criteria into the objective function of the FCAM model, and calculated China's provinces CEA in 2030 by using MFCAM. Then, we measured China's provinces CEI in 2030 and the reduction of CEI in 2030 compared to 2015. Finally, we also classified China's province from a single dimension and two-dimension, respectively. The main conclusions are as follows.

When China's CEI in 2030 is 65\% lower than that in 2005, we conclude that China's overall carbon emissions in 2030 will be 17567.9 Mt. We used the entropy method to calculate the CEA of Each Province in China in 2030 based on the "principle-dimension" multi-criteria. The results showed that the southern provinces had higher CEA than the northern provinces. 
We obtained China's provinces the final CEA by embedding the CEA results of "principle-dimension" multi-criterion into the objective function of the FCAM. Guangdong has the largest final CEA due to its large population, developed economy, and high energy efficiency. Gansu, Qinghai, Ningxia, and Hainan are the four provinces with the least final CEA.

The regions of Guizhou, Inner Mongolia, Ningxia, Xinjiang, Shaanxi, and Shanxi will take on greater responsibility for carbon reduction in the future. On the contrary, Tianjin, Qinghai, Guangxi, and Beijing will be able to sell CEA in the future.

From the single dimension of CEI reduction, according to CEI reduction, Chinese provinces are divided into three categories: small emission reduction task, moderate emission reduction task, and high emission reduction tasks. Among them, most provinces with high emission reduction tasks are resource provinces. From the two dimensions of economic development and CEI reduction, the provinces are divided into four zones, which are high economic development with low emission reduction task zones, high economic development with high emission reduction task zones, low economic development with low emission reduction task zones, and low economic development with high emission reduction task zones, respectively.

Based on the above research conclusions, we propose the following policy recommendations.

The government needs to provide different policies for China's provinces to reduce emissions. Considering that some provinces need to purchase CEA, the others need to sell CEA, carbon emission rights are likely to be capitalized. Therefore, the government must establish a carbon asset management company and design a feasible mechanism to promote cooperation in carbon emission reduction between provinces.

Resource provinces with high emission reduction tasks should propose precise carbon emission reduction plans. For example, considering the resource endowments of Xinjiang, Inner Mongolia, and Shaanxi, clean energy such as solar and wind power should be developed in their power industry.

The high economic development with low emission reduction task zones should use their double advantages to achieve rapid economic development as soon as possible while achieving emission reduction tasks. The low economic development with low emission reduction task zones should take advantage of the low pressure of emission reduction and actively develop the economy. The high economic development with high emission reduction task zones should make use of the advantages of economic development to improve the technology of high-pollution industries, increase innovation, improve efficiency, and achieve emission reduction tasks. The low economic development with high emission reduction task zones should cultivate the leading industry with embeddedness as soon as possible. For example, the production of characteristic ecological products can transform the driving force of economic development and realize industrial transformation and upgrading.

Ethics Approval and Consent to Participate Not applicable.

\section{Consent to Publish Not applicable.}

Authors Contributions Conceptualization, F.W.; methodology, X.G.; software, X.G.; investigation, X.G.; data curation, X.G.; writing - original draft preparation, X.G.; writing - review and editing, F.W.; funding acquisition, F.W. All authors have read and agreed to the published version of the manuscript.

Funding This research was funded by the National Natural Science Foundation of China under Grant number 71673217.

Competing Interests The authors declare no interest.

Availability of data and materials All data generated or analysed during this study are included in this published article.

\section{References}

Beasley J E (2003) Allocating fixed costs and resources via DEA. European Journal of Operational Research 147: 198-216.

Cui, LB, Fan Y, Zhu L, Bi QH (2014). How will the emissions trading scheme save cost for achieving China's 2020 carbon intensity reduction target?. Applied Energy 136: 1043-1052.

Elzen MD, Lucas P and Vuuren DV (2005) Abatement costs of post-Kyoto climate regimes. Energy Policy 33: 2138-2151.

Fang K, Wang QF, Ye RK, Zhou Y (2018) Allocating China's carbon emission allowance to the provincial quotas in the 
context of the Paris Agreement. Acta Scientiae Circumstantiae 38(3): 1224-1234.

Fang K, Zhang Q, Long Y, Yoshida Y, Sun, L, Zhang HR, Dou Y, Li S (2019). How can China achieve its Intended Nationally Determined Contributions by 2030? A multi-criteria allocation of China's carbon emission allowance. Applied Energy 241: 380-389.

Feng ZY, Tang WH, Niu ZW, Wu QH (2018) Bi-level allocation of carbon emission permits based on clustering analysis and weighted voting: a case study in China. Applied Energy 228: 1122-1135,

Feng, Y, Lu ZN (2016) Regional Allocation of Carbon Emission Rights in Perspective of Variant Responsibility. Soft Science 30: 122-126.

Fu JY, Huang F (2016) Study on the Distribution Efficiency of CO2 Emissions in China's Carbon Trading Market. China Population, Resources and Environment 26: 1-9.

Gomes EG, Lins MPE (2008) Modelling undesirable outputs with zero sum gains DEA models. Journal of the Operational Research Society 59: 616-623.

Han R, Tang BJ, Fan JL, Liu LC, Wei YM (2016) Integrated weighting approach to carbon emission quotas: an application case of Beijing-Tianjin-Hebei region. Journal of Cleaner Production 131: 448-459.

Han R, Yu BY, Tang BJ, Liao H, Wei YM (2017). Carbon emissions quotas in the Chinese road transport sector: A carbon trading perspective. Energy Policy 106: 298-309.

Kong YC, Zhao T, Yuan R, Chen C (2019) Allocation of carbon emission quotas in Chinese provinces based on equality and efficiency principles. Journal of Cleaner Production 211: 222-232.

Li L, Ye F, Li Y, Tan KH (2018). A bi-objective programming model for carbon emission quota allocation: Evidence from the Pearl River Delta region. Journal of Cleaner Production 205: 163-178.

Li XS, Lu Y, Wang HJ, Feng M, Lou F, Zhang BB, Li SS (2020) Research on the Potential Growth of the Chinese Economy in the Next 15 Years and the Main Goals and Indicators of Economic and Social Development during the 14th Five-Year Plan Period. China Industrial Economics 4: 5-22.

Li Y, Wei Y, Zhang X, Tao Y (2020) Regional and provincial CO2 emission reduction task decomposition of China's 2030 carbon emission peak based on the efficiency, equity and synthesizing principles. Structural Change and Economic Dynamics.

Ma M, Yan R, Du Y, Ma X, Cai W, Xu P (2017) A methodology to assess China's building energy savings at the national level: an IPAT-LMDI model approach. Journal of cleaner production 143: 784-793.

Pan X, Teng F and Wang G (2014) Sharing emission space at an equitable basis: Allocation scheme based on the equal cumulative emission per capita principle. Applied Energy 113: 1810-1818.

Qin Q, Liu Y, Li X, Li H (2017). A multi-criteria decision analysis model for carbon emission quota allocation in China's east coastal areas: efficiency and equity. Journal of Cleaner Production 168: 410-419.

Schmidt RC, Heitzig J (2014) Carbon leakage: Grandfathering as an incentive device to avert firm relocation. Journal of Environmental Economics and Management 67: 209-223.

Shan HJ (2008) Re-estimating the Capital Stock of China:1952 2006. The Journal of Quantitative \& Technical Economics 25: $17-31$.

Shan YL, Guan DB, Zheng HR, Qu JM, Li Y, Mi ZF, Liu Z, Zhang Q (2018) China CO2 emission accounts 1997-2015. Scientific data 5: 170201.

Shang HL, Smith PW, Bijak J, Wiśniowski A (2016) A multilevel functional data method for forecasting population, with an application to the United Kingdom. International Journal of Forecasting 32(3): 629-649.

Shannon CE (1949) Communication theory of secrecy systems. Bell System Technical Journal 28: 656-715.

Wang K, Li MJ (2013) DEA-based Carbon Emission Allowance Allocation Modeling and Application. Journal of Beijing Institute of Technology (Social Sciences Edition) 15: 7-13.

Wu J, Ma XZ, Wang Z (2010) Province emission permits quota allocations in China. Quaternary Sciences 30: 481 -488.

Yang Y, Cai WJ, Wang C, Wang SQ (2012) Regional Allocation of CO2 Intensity Reduction Targets Based on Cluster Analysis. Adv Clim Change Res 3(4):220-228.

Yi WJ, Zou LL, Guo J, Wang K, Wei YM (2011) How can China reach its CO2 intensity reduction targets by 2020? A regional allocation based on equity and development. Energy Policy 39: 2407-2415.

Zeng S, Xu Y, Wang L, Chen J, Li Q (2016). Forecasting the allocative efficiency of carbon emission allowance financial assets in China at the provincial level in 2020. Energies 9(5): 329.

Zhang XP, Cheng XM (2009) Energy consumption, carbon emissions, and economic growth in China. Ecological Economics 68: 2706-2712.

Zhang YJ, Hao JF (2017) Carbon emission quota allocation among China's industrial sectors based on the equity and 
602

603

604

605

606

607

608

609

610

611

612

613

efficiency principles. Annals of Operations Research 255: 117-140.

Zhang YJ, Wang AD and Da YB (2014) Regional allocation of carbon emission quotas in China: Evidence from the Shapley value method. Energy Policy 74: 454-464.

Zhao R, Min N, Geng Y, He Y (2017) Allocation of carbon emissions among industries/sectors: An emissions intensity reduction constrained approach. Journal of cleaner production 142: 3083-3094.

Zhou P, Wang M (2016) Carbon dioxide emissions allocation: A review. Ecological Economics 125: 47-59.

Zhou P, Zhang L, Zhou DQ, Xia WJ (2013). Modeling economic performance of interprovincial CO2 emission reduction quota trading in China. Applied Energy 112: 1518-1528.

Zhou X, Guan X, Zhang M, Zhou Y, Zhou M (2017) Allocation and simulation study of carbon emission quotas among China's provinces in 2020. Environmental Science and Pollution Research 24(8): 7088-7113.

Zhou Z, Liu C, Zeng X, Jiang Y, Liu W (2018). Carbon emission performance evaluation and allocation in Chinese cities. Journal of Cleaner Production 172: 1254-1272. 
Figures

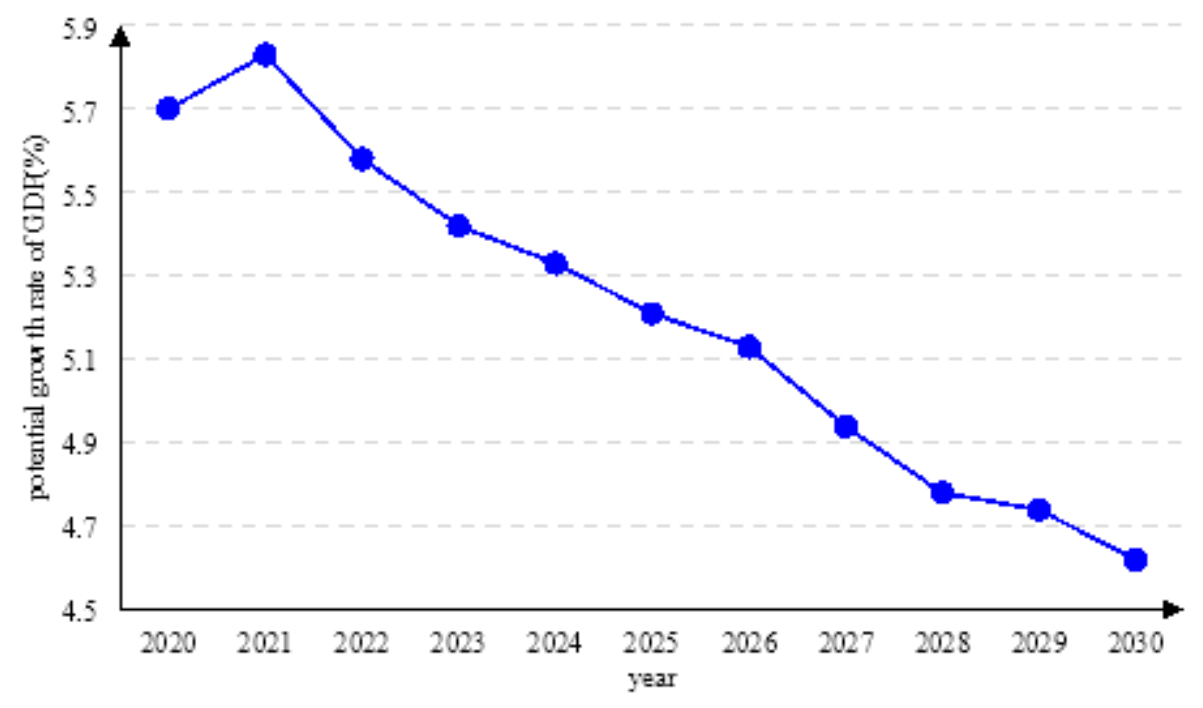

Figure 1

Forecast values of China's potential economic growth rate from 2020 to 2030 


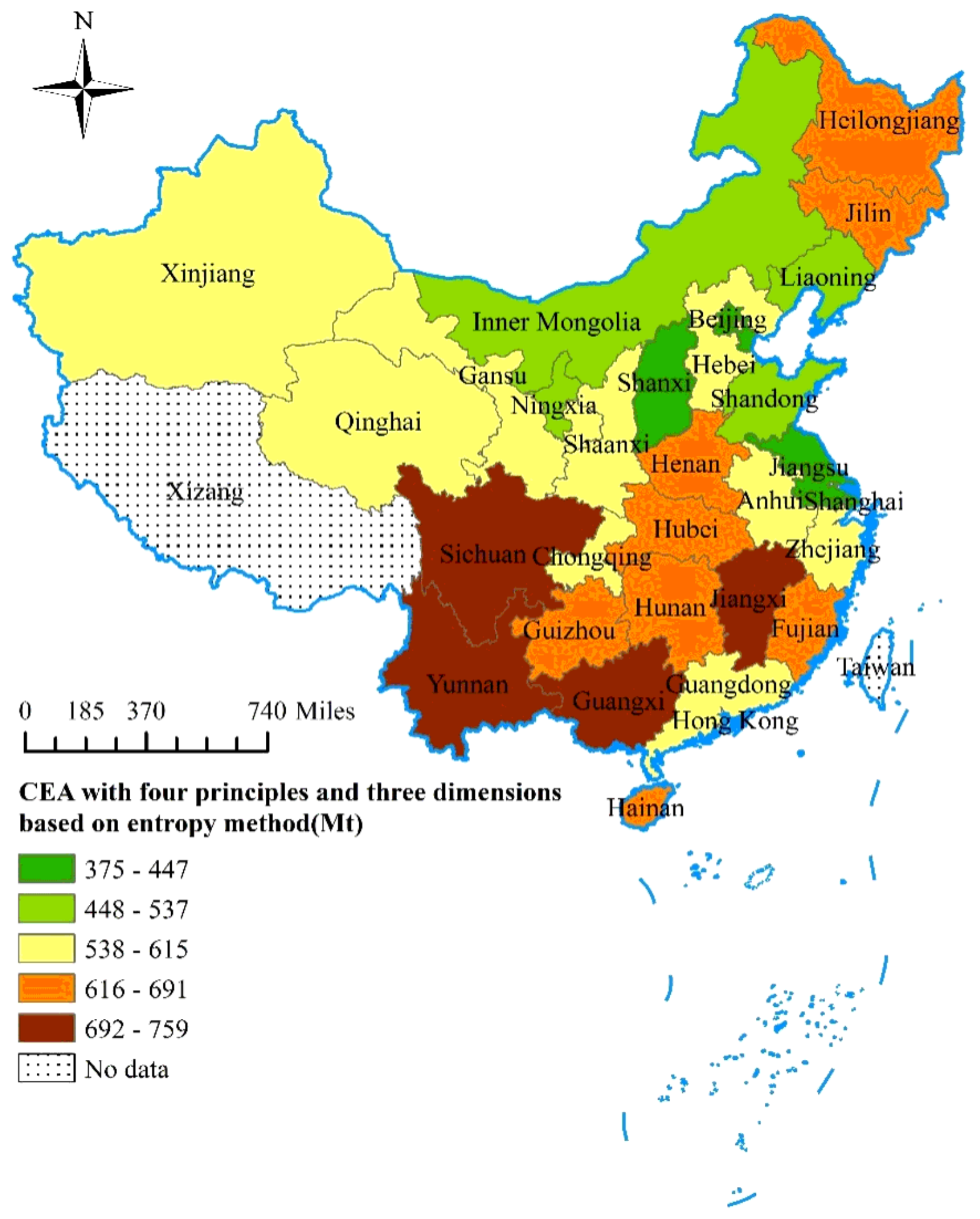

Figure 2

Provincial CEA based on "principles dimension" multi-criteria in 2030. Note: The designations employed and the presentation of the material on this map do not imply the expression of any opinion whatsoever on the part of Research Square concerning the legal status of any country, territory, city or area or of its authorities, or concerning the delimitation of its frontiers or boundaries. This map has been provided by the authors. 


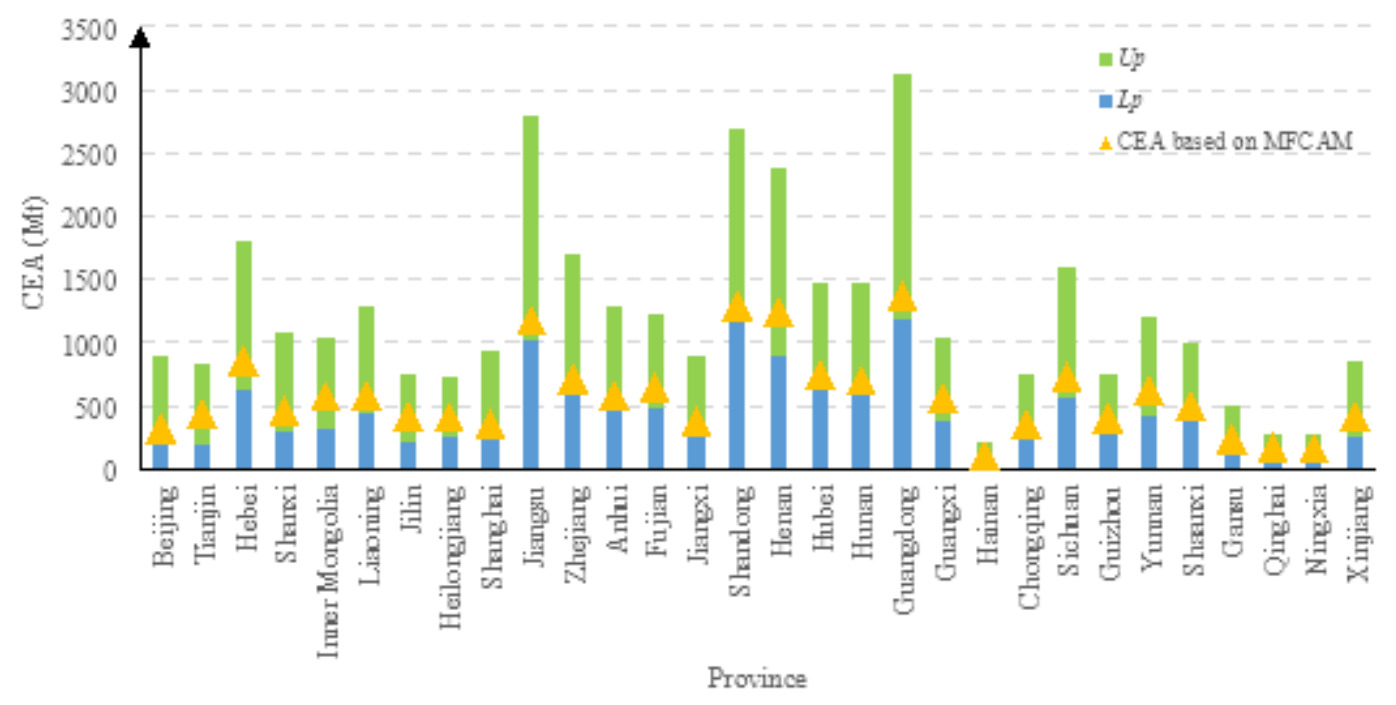

Figure 3

Provincial final CEA in 2030 based on MFCAM

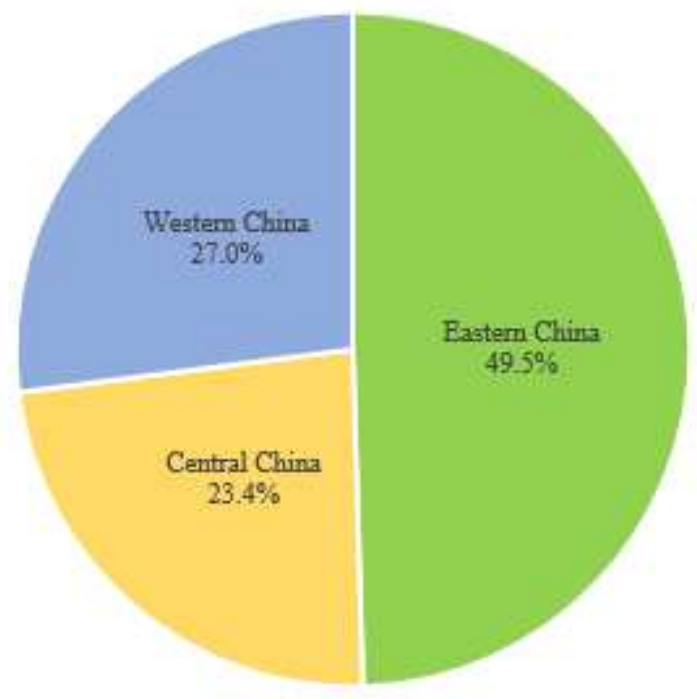

Figure 4

The proportion of China regional final CEA in 2030 based on MFCAM 


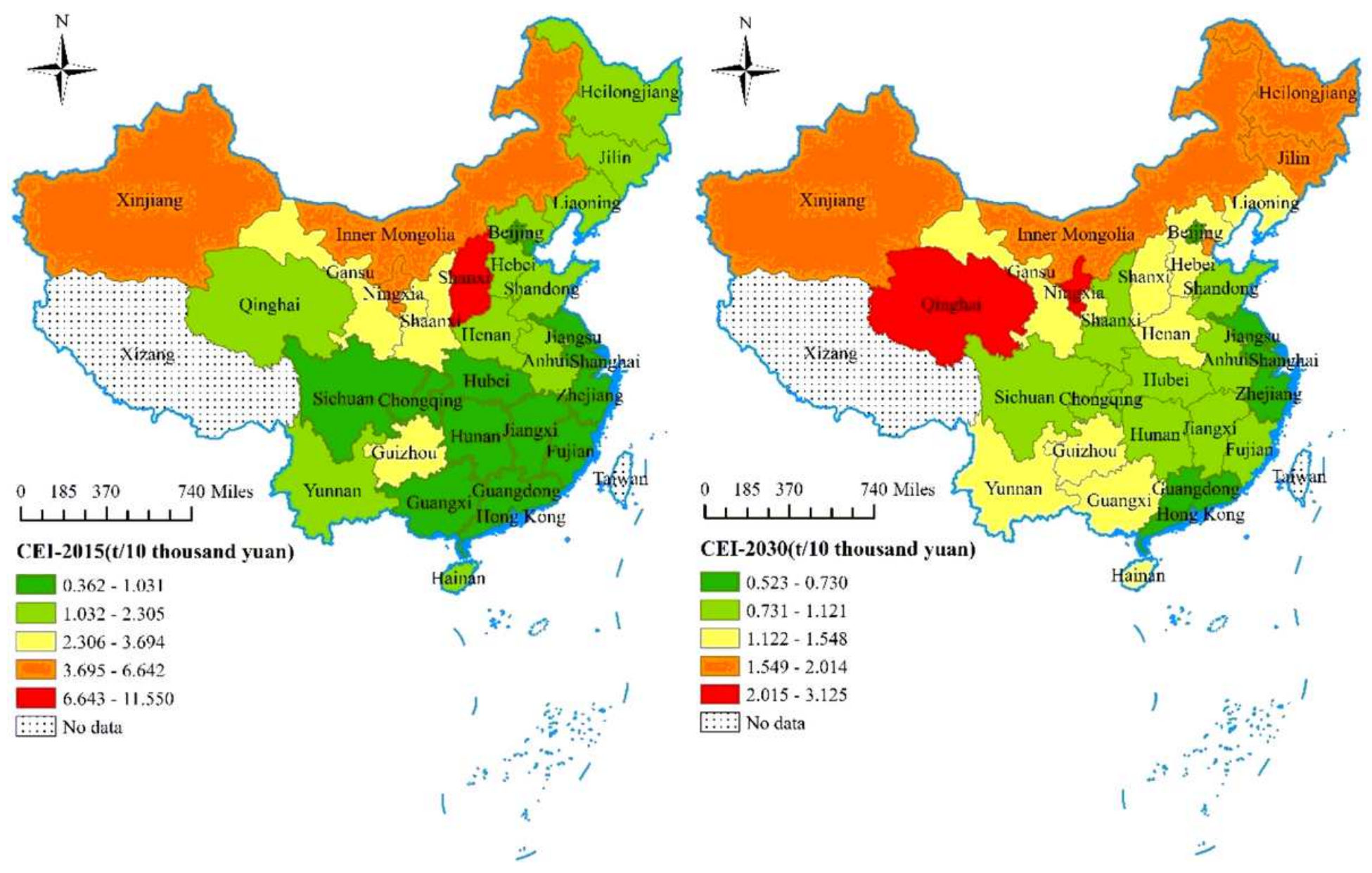

Figure 5

The distribution of CEI of China's provinces in 2015 and 2030. Note: The designations employed and the presentation of the material on this map do not imply the expression of any opinion whatsoever on the part of Research Square concerning the legal status of any country, territory, city or area or of its authorities, or concerning the delimitation of its frontiers or boundaries. This map has been provided by the authors. 


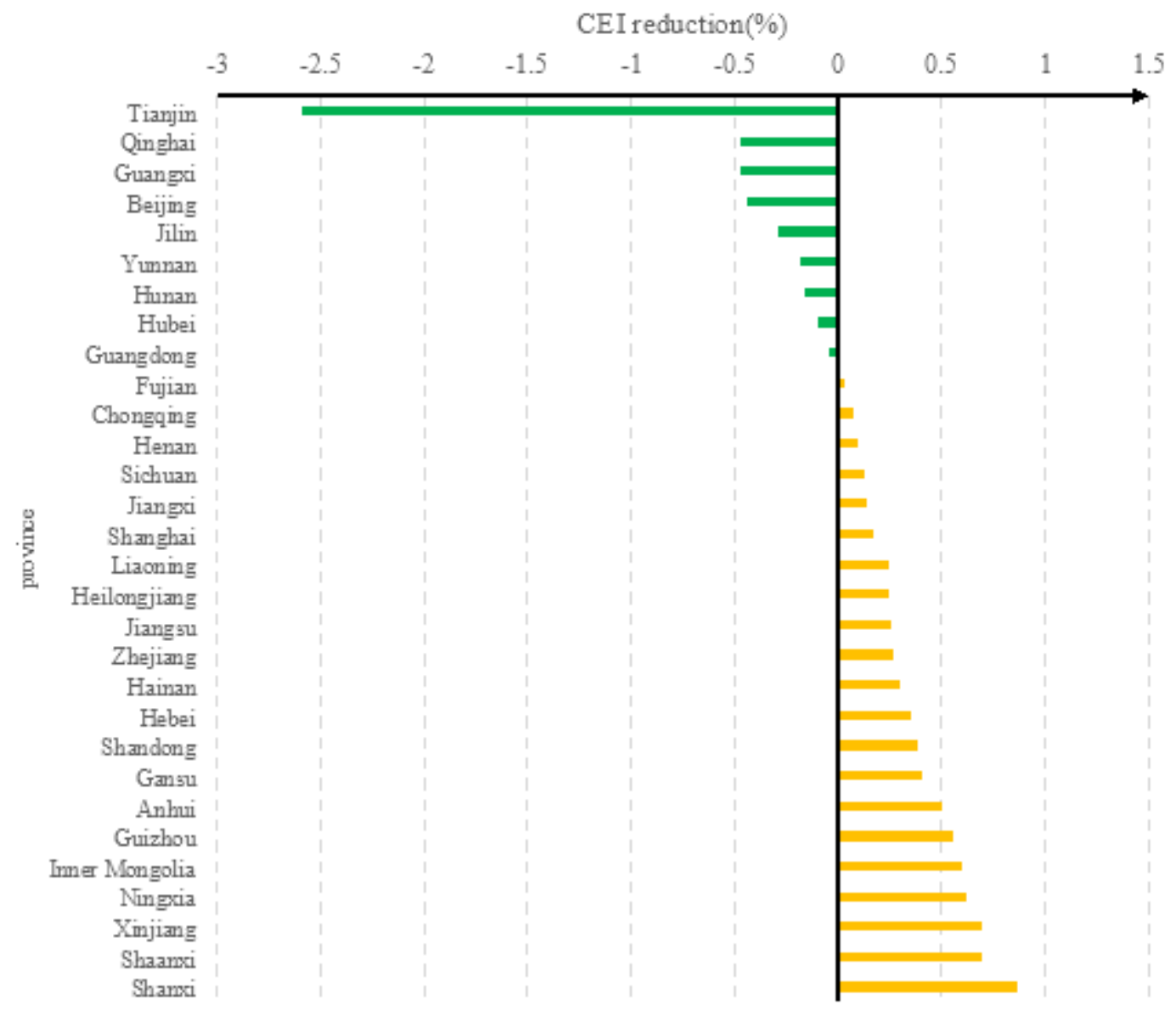

Figure 6

The CEl reduction of China's provinces during 2015-2030 


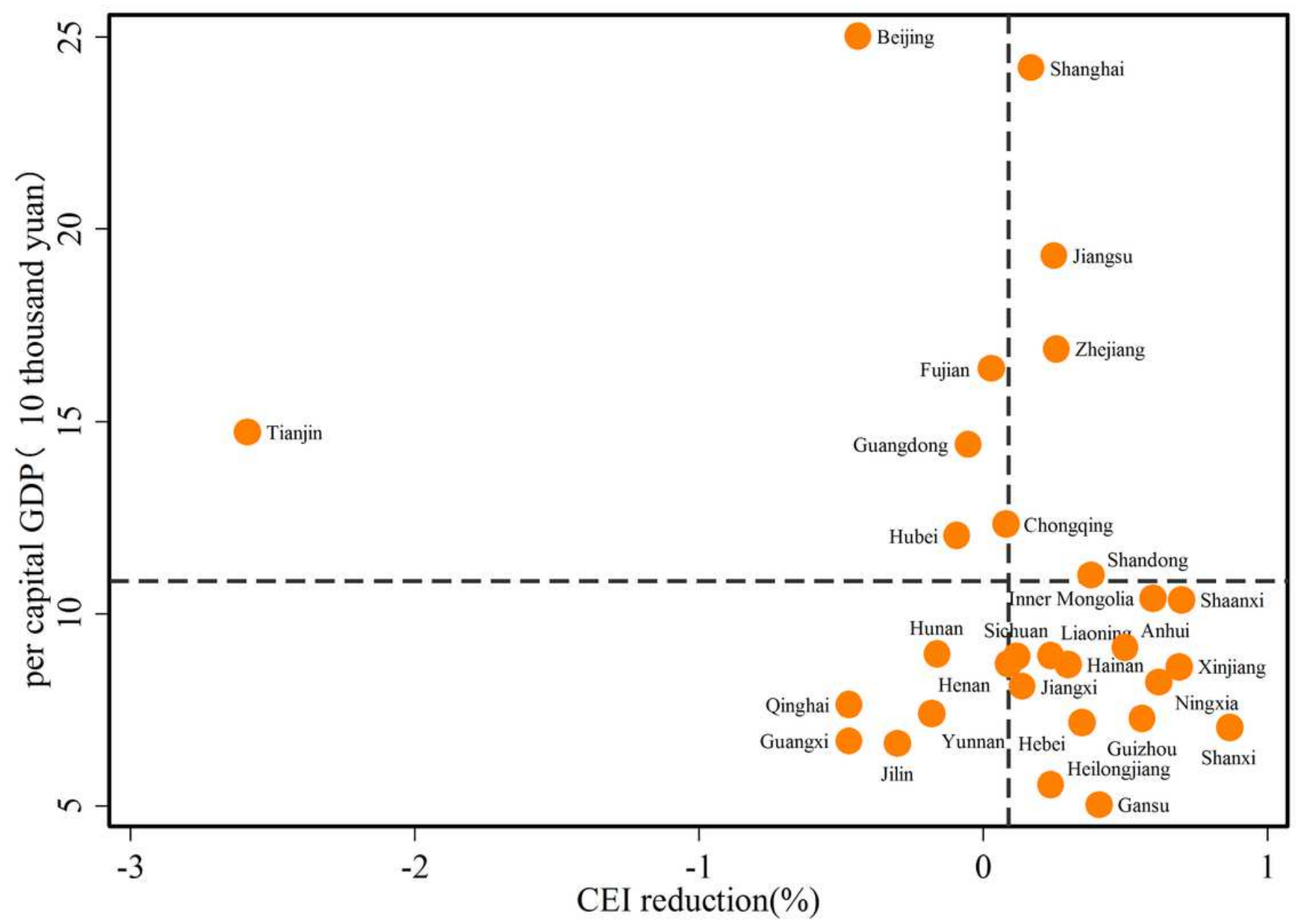

Figure 7

The scatter plot of per capital GDP and carbon intensity reduction in 2030 